Aus der Abteilung für Neuroimmunologie Prof. Dr. med. A. Flügel im Institut für Multiple-Sklerose-Forschung der Medizinischen Fakultät der Universität Göttingen

\title{
Die Bedeutung von Serum-Antikörpern gegen Myelinproteine vor Erstmanifestation einer Multiplen Sklerose
}

\section{INAUGURAL DISSERTATION}

zur Erlangung des Doktorgrades der Medizinischen Fakultät der Georg-August-Universität zu Göttingen

\author{
vorgelegt von \\ Corinna Franke
}

aus

Rosenheim

Göttingen 2014 


\section{Dekan:}

I. Berichterstatter/in:

II. Berichterstatter/in:

III. Berichterstatter/in:
Prof. Dr. rer. nat. H. K. Kroemer

Prof. Dr. med. A. Chan

PD Dr. K. Hein

Prof. Dr. M. Schön

Tag der mündlichen Prüfung: 22.10 .2014 


\section{Inhaltsverzeichnis}

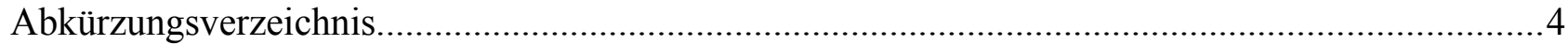

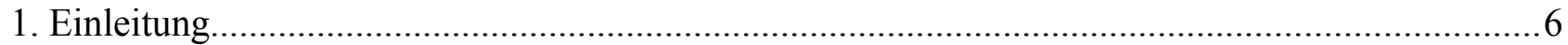

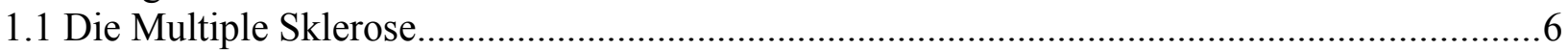

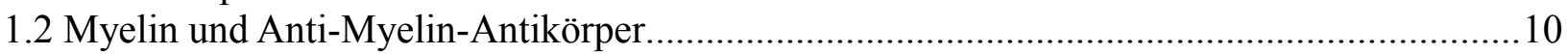

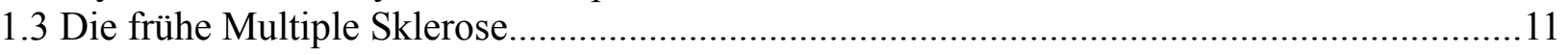

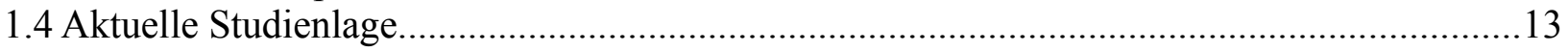

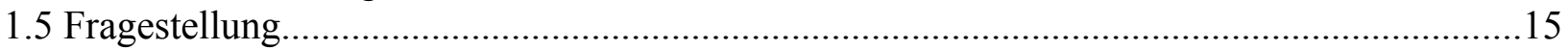

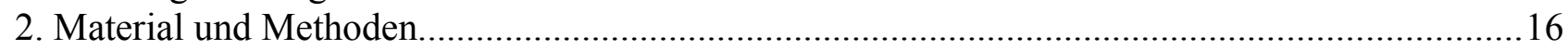

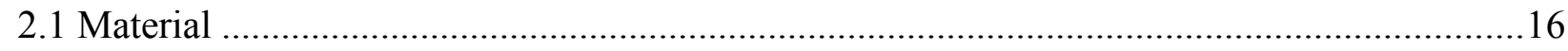

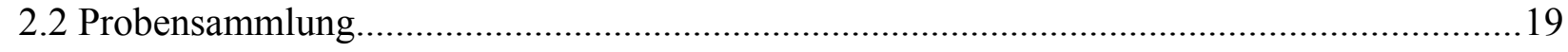

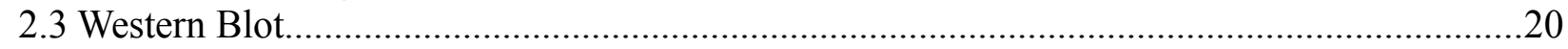

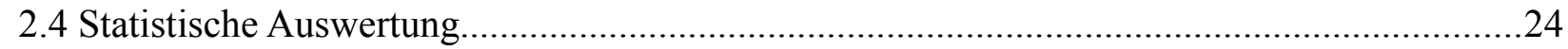

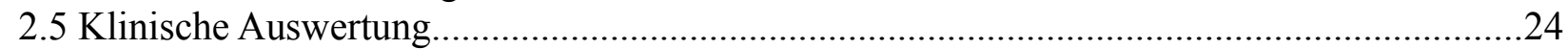

3. Ergebnisse

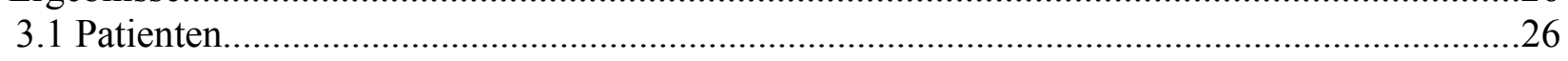

3.2 Qualität der Proben......................................................................................................29

3.3 Vorkommen von Anti-MOG und Anti-MBP-Antikörpern im Western Blot............................30

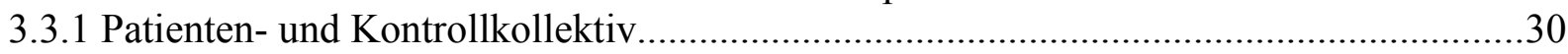

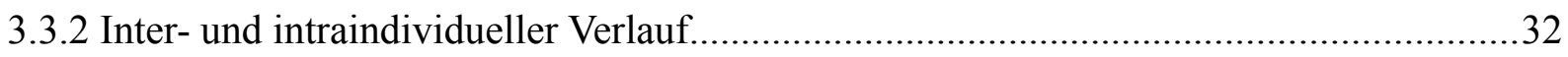

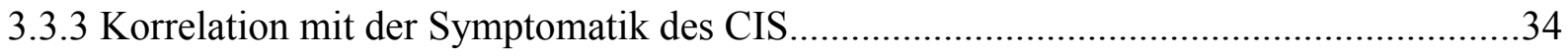

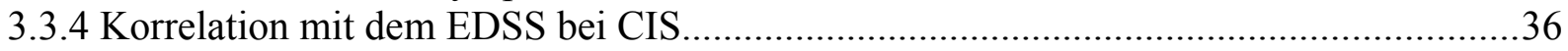

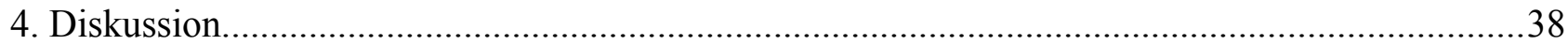

4.1 Anti-MOG- und Anti-MBP-Antikörper als prädiktive Marker...........................................38

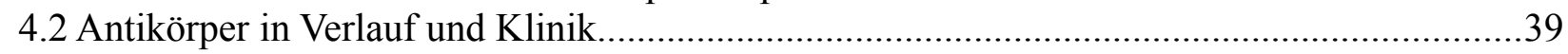

4.3 Wertigkeit des Western Blot in dieser Fragestellung.....................................................40

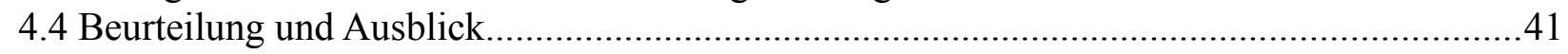

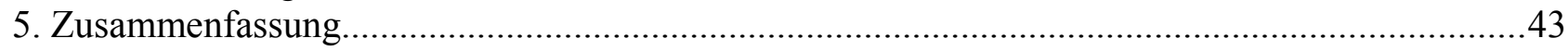

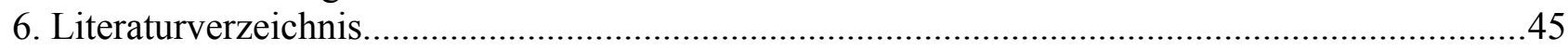




\section{Abkürzungsverzeichnis}

aa

aminoacid (= Aminosäure)

ACCN1 amiloride-sensitive cation channel neuronal 1, ein Protein eines MSassoziierten Gens)

ADEM akute disseminierte Enzephalomyelitis

AK Antikörper

AP alkalische Phosphatase

APS Ammoniumpersulfat

Aqua dest. Aqua destillata (= Destilliertes Wasser)

BCIP 5-Brom-4-Chlor-3-Indoxylphosphat

CIS $\quad$ clinically isolated syndrome (= klinisch isoliertes Syndrom)

CLEC16A C-type lectin domain family 16, ein Protein eines MS-assoziierten Gens

DSS disability status scale, ein Vorläufer des EDSS (s.u.)

EAE experimental autoimmune encephalomyelitis (= experimentelle

Autoimmunenzephalitis)

EBV Epstein-Barr-Virus

EDSS extended disability status scale, standartisierte Gradeinteilung der Schwere körperlicher Behinderungen

EDTA ethylenediaminetetraacetic acid (= Ethylendiamintetraessigsäure)

ELISA enzyme linked immunosorbent assay (= enzymgekoppeltes, antikörperbasiertes Nachweisverfahren für Proteine)

FACS fluorescence activated cell sorting (= Durchflusszytometrie)

HBV Hepatitis B- Virus

HHV humanes Herpesvirus

HLA humanes Leukozyten- Antigen, ein Protein eines MS-assoziierten Gens

HSV Herpes simplex- Virus

Ig Immunglobulin

IL2 (-7) RA Interleukin-2 (-7)-Rezeptor-alpha, ein Protein eines MS-assoziierten Gens i.v. intravenös

kDA kilo-Dalton 
KIR4.1 spezieller Kaliumkanal, Antikörper gegen diesen sind MS-assoziiert

M molar

$\mathrm{mA} \quad$ Milliampere

MAB monoclonal antibody (= monoklonaler Antikörper)

MBP Myelin-basisches Protein

$\mu \mathrm{l} \quad$ Mikroliter

$\mu \mathrm{g} \quad$ Mikrogramm

MOG Myelin-Oligodendrozyten-Glykoprotein

MRT Magnetresonanztomographie

MS Multiple Sklerose

MSTKG Multiple Sklerose Therapie Konsensus Gruppe

$\mathrm{Na} \quad$ Natrium

$\mathrm{NaCl} \quad$ Natriumchlorid

NBT Nitroblau-Tetrazoliumchlorid, ein Redox-Farbstoff

PBS phosphate buffered saline (= phosphatgepufferte Salzlösung), Pufferlösung

$\mathrm{pH} \quad$ potentia Hydrogenii

PNS Peripheres Nervensystem

RIS radiologically isolated syndrom (= radiologisch isoliertes Syndrom)

SDS Sodium Dodecyl Sulfate, bewirkt eine Denaturierung von Proteinen

TBS $\quad$ tris buffered saline (= trisgepufferte Salzlösung), Pufferlösung

TEMED Tetramethylethylendiamin, ein Katalysator bei der Herstellung von Polyacrylamidgel

TRIS Tris(hydroxymethyl)-aminomethan, ein Pufferbestandteil

TWEEN Polyoxyethylen-sorbitan-monolaurat, ein Entferner unspezifischer Antikörperbindungen

VZV Varizella-Zoster-Virus

ZNS Zentrales Nervensystem 


\section{Einleitung}

\subsection{Die Multiple Sklerose}

Die Multiple Sklerose ist heute bekannt als häufigste entzündliche Erkrankung des ZNS und wichtigste nicht-traumatische Ursache körperlicher Behinderung des jungen Erwachsenenalters.

Als Erstbeschreiber der Multiplen Sklerose gilt Jean-Martin Charcot mit seinem Werk „Histologie de la sclérose en plaques“ von 1868, man findet in diesem Zusammenhang aber auch andere Namen, wie zum Beispiel Cruveilhier oder Carlswell, welche in ihren Werken der MS sehr ähnliche Krankheitsbilder beschrieben (Charcot 1868).

An der Universität Göttingen wurde schon 1849 von Frerichs über die Hirnsklerose unterrichtet, welche aber erst post mortem diagnostiziert werden konnte, nachdem man in den Gehirnpräparaten verstorbener Patienten verhärtete Plaques finden konnte. Diese Beobachtungen gaben dann auch den Namen „Sklerose“. Auch hat sich der beschreibende Terminus Encephalomyelitis disseminata etabliert, im Folgenden wird der Begriff MS verwendet.

So wie die entzündlichen Herde bei der MS im gesamten Zentralen Nervensystem auftreten können, umfasst die Symptomatik ebenfalls ein umfangreiches neurologisches Spektrum. Als typisch gelten Parästhesien, Paresen, Ataxien sowie Doppelbilder oder Visusminderung. Auch Miktions- und Sexualfunktionsstörungen werden beschrieben, seltener psychische oder kognitive Störungen wie z.B. depressive Episoden oder Konzentrationsschwäche. Als Charcot-Trias wurde der Symptomkomplex aus Intentionstremor, Nystagmus und skandierender Sprache bekannt, das Lhermitte-Syndrom ist ein bei etwa 1/3 aller MSPatienten vorkommendes begleitendes Schmerzsyndrom. Das Krankheitsbild der MS ist folglich mannigfaltig und kann einen höchst malignen oder auch einen sehr benignen Charakter aufweisen. Variable Muster der Krankheitsaktivität geben auch unterschiedliche klinische Verlaufsformen vor. Am häufigsten ist die schubförmige Variante, welche durch klare Abgrenzung der Schübe und vollständige oder teilweise Remission zwischen den Krankheitsattacken gekennzeichnet ist. Oft erfolgt in einer späteren Phase der Krankheit ein Übergang der schubförmigen in eine progrediente Verschlechterung, also in einen sekundär 
chronisch progredienten Verlauf. Dies ist in einem Zeitraum von 10-15 Jahren bei 30-50\% der Patienten der Fall. Seltener ist der primär chronisch progrediente Verlauf, bei dem von Anfang an eine kontinuierliche und meist schnelle Progression der Krankheitssymptome erfolgt (Gold und Rieckmann 2004; Schmidt und Hoffmann 2006).

Der Grundsatz der Diagnosestellung einer MS ist der Nachweis entzündlicher Herde im ZNS, die sowohl in zeitlicher als auch in örtlicher Dissemination auftreten müssen.

Aktuell gelten die 2001 entwickelten und 2005 sowie erneut 2012 revidierten und dem Forschungsstand angepassten Diagnosekriterien nach McDonald, welche ein System aus Klinik, Liquoruntersuchung und MRT-Befunden bilden, wobei mit der MRT heutzutage sowohl die zeitliche als auch die örtliche Dissemination dargestellt werden kann.

Das Geschlechtsverhältnis der Erkrankten w:m liegt heute bei 2-3:1, wobei für den Beginn der Erkrankung ein deutlicher Altersgipfel zwischen 20 und 40 Jahren besteht (Wingerchuk und Weinshenker 2000). Die Inzidenz der MS zeigte über die letzten Jahre eine deutliche Zunahme, wobei insbesondere die weiblichen Patienten zahlreicher werden (Maghzi et al. 2010, Alonso und Hernán 2008). In Deutschland wird ein Vorkommen von 30-60/100 000 geschätzt (Orton et al. 2010, Kurtzke 2000 a; Hein und Hopfenmüller 2000). Eine steigende Prävalenz mit der Entfernung vom Äquator wurde schon früh beschrieben, allerdings ist dieser Effekt, wie auch der Anstieg der Inzidenz der MS im letzten Jahrhundert, womöglich zum Teil auch auf eine verbesserte Diagnostik und Therapie in den Industrieländern zurückzuführen. Insgesamt bestehen geographische Schwankungen von 1:100 000 in Japan bis 309:100 000 auf den Orkney- Inseln (Compston 1998, Sadovnick et al. 1998). Insgesamt sind die Ursachen, die zur Entmarkung der Nerven im ZNS führen, nach heutigem Forschungsstand multifaktoriell; verschiedene Hypothesen zur Pathogenese sind bislang durch zahlreiche Forschungsreihen unterstützt worden.

Erste Hinweise auf eine genetische Ursache wurden bei der Beobachtung von Familien gefunden. So nimmt die Wahrscheinlichkeit, an MS zu erkranken mit steigendem Verwandtschaftsgrad zu einem Patienten von $0,88 \%$ bei Verwandten 3 . Grades bis $38 \%$ bei monozygoten Zwillingen deutlich zu (Sadovnick et al. 1999). Besteht eine Verwandtschaft zu mehreren und männlichen MS-Patienten, steigt die Wahrscheinlichkeit zu erkranken, 
signifikant (Prokopenko et al. 2003). Das Risiko der Normalbevölkerung wurde auf 0,66\% errechnet. Auf molekularbiologischer Ebene konnten bislang bereits mehrere krankheitsassoziierte Gene und insbesondere Genkombinationen gefunden werden. Die Genregion für Proteine der HLA-Familie auf dem Chromosom 6 stellt einen Fokus dar. Eine Assoziation mit MS ist für HLA-DR2, HLA-A3, -B7 beschrieben. Mittlerweile wurde auch für nicht-HLA-Gene ein Zusammenhang mit der Erkrankung gezeigt, hierbei sind vor allem IL2RA und IL7RA, CLEC16A und ACCN1 zu nennen (Hafler et al. 2007, Weber et al. 2008, Hoe et al. 2010, Bernardinelli et al. 2007, Nischwitz et al. 2010, Sawcer et al. 2011). Auch zahlreiche andere immunrelevante Gene scheinen eine Rolle bei der Krankheitsentstehung zu besitzen. Eine unvollständige Penetranz sowie variable Expressivität erscheinen dabei gesichert.

Auch die geographischen Unterschiede in der Prävalenz deuten auf eine genetische Komponente hin. Allerdings haben diverse Migrationsstudien gezeigt, daß sich das Erkrankungsrisiko bei Einwanderung in sehr jungem Alter an das der Bevölkerung im neuen Heimatland angleicht (Wallin et al. 2004; Kurtzke 2000 b). Folglich muss auch von einer nicht unerheblichen Beteiligung von Umweltfaktoren ausgegangen werden.

Als Umweltfaktoren zählt neben Ernährung, Lebensweise, der Jahreszeit der Geburt und der Art des Metabolismus auch der Kontakt mit Krankheitserregern, insbesondere in der Kindheit. Verschiedene Hypothesen zur Krankheitsgenese der MS setzen eine virale Beteiligung voraus. Im Verdacht einer Assoziation mit der MS stehen vor allem Herpesviren wie Epstein-Barr-Virus, HBV, HSV, VZV sowie Paramyxomaviren, Coronaviren und Papovaviren. Eine These geht von einer Persistenz und rezidivierender Reaktivierung eines Erregers in Zellen des ZNS aus; eine andere geht von einer peripheren Infektion aus, welche die Aktivierung von autoreaktiven T-Zellen und deren Migration ins ZNS auslösen. Auch molekulare Mimikry bestimmter Viren und daraus folgend die Förderung autoreaktiver Zellen und Antikörper ist ein theoretischer Ansatz.

Insgesamt betrachtet kann bei der MS von einer genetischen Disposition in Kombination mit auslösenden Umweltfaktoren ausgegangen werden.

Die mikroskopische Betrachtung der ZNS-Läsionen bei Patienten mit aktiv demyelinisierender MS läßt die Einteilung in 4 verschiedene Kategorien zu, welche auf 
ebenfalls unterschiedliche Pathogenese hindeuten:

I. Makrophagen-assoziierte Entmarkung

II. Antikörper-vermittelte Entmarkung mit aktivierten Komplementfaktoren

Neben der primären Demyelinisierung kommt auch die Apoptose als primärer Prozess der Läsionen vor:

III. Oligodendrozytenapoptose und Oligodendrogliopathie

IV. Primäre Oligodendrozytendegeneration der weißen Substanz

(Lucchinetti et al. 2000; Lassmann et al. 2001; Keegan et al. 2005)

Die unterschiedlichen Muster wurden bei verschiedenen Patienten gefunden; bei jedem einzelnen Patienten ähneln sich die Läsionen.

Diese Unterteilung der MS in Subgruppen wird unterstützt durch das heterogene Ansprechen der einzelnen Patienten auf unterschiedliche Therapieansätze. Eine frühe Methode zur Unterscheidung von Subtypen könnte eine gezielte und effektive Therapie ermöglichen.

Die Pathogenese der MS ist in erster Linie gekennzeichnet durch die Entstehung und Aktivierung autoreaktiver T-Zellen in der Peripherie, deren Überwindung der Blut-HirnSchranke und schließlich die lokale Aktivierung durch ein dort präsentiertes Antigen mit folgender Immunkaskade und somit Demyelinisierung und axonaler Schädigung im ZNS. Das sogenannte epitope spreading bezeichnet die spontane Aktivierung von T-Zellen auf verschiedene weitere Epitope des Myelins nach Beginn der Immunreaktion.

Die Wichtigkeit einer gestörten humoralen Immunantwort mit B-Zellen und Antikörpern ist mittlerweile vielfach belegt, zum Beispiel durch die häufig erhöhten Immunglobuline im Liquor von MS-Patienten, was anfangs eher als Epiphänomen einer aktiven MS betrachtet wurde. Auch ist die Wirksamkeit von Therapien wie der Plasmapherese zu nennen (Gold und Rieckmann 2004; Schilling et al. 2006; Linker et al. 2007) sowie die mikroskopischen Läsionen der Kategorie II. Wie oben beschrieben bestehen diese aus Antikörper-vermittelter Entmarkung mit aktivierten Komplementfaktoren. Eine Bedeutung von Antikörpern in der Pathogenese konnte bereits auch für die Neuromyelitis optica, eine ebenfalls demyelinisierende Erkrankung, nachgewiesen werden (Lucchinetti et al. 2002; Gold und Linington 2002). Sowohl im Liquor von MS-Patienten als auch im ZNS-Gewebe wurden 
Anti-Myelin-Antikörper wie auch andere spezifische Antikörper, wie zum Beispiel der KIR4.1-AK, gefunden (Srivastava et al. 2012). Eine tatsächliche Beteiligung des humoralen Immunsystems an der Pathogenese der MS gilt somit heutzutage als bewiesen (Hafler et al. 2005). Daher wird in Bezug auf eine verbesserte und frühere Diagnostik der Erkrankung nach relativ einfach nachzuweisenden assoziierten Antikörpern gesucht.

\subsection{Myelin und Anti-Myelin-Antikörper}

Der der progressiven Symptomatik zugrunde liegende Prozess ist in erster Linie eine fortschreitende Entmarkung sowie eine direkte axonale Schädigung der Nervenfasern des ZNS. Zur schnelleren Erregungsüberleitung sind die Nervenfasern ummantelt von einer mehrschichtigen fettreichen Substanz, dem Myelin, und somit von der Erregung isoliert. Unterbrochen wird diese Umscheidung von den sog. Ranvier'schen Schnürringen, Zonen ohne Ummantelung, über welche die Erregung saltatorisch übergeleitet wird. Dadurch kann im ZNS eine Überleitungsgeschwindigkeit von über $300 \mathrm{~m} / \mathrm{s}$ erreicht werden.

Den Namen "Myelin", vom griechischen myelós (Mark) abgeleitet, prägte schon 1856 Virchow, welcher dieses allerdings für eine Art Bindegewebe hielt. Hierfür bilden die Oligodendrozyten lange Ausläufer, die sich mehrfach spiralförmig um eine Nervenfaser wickeln und bis zu 50 Schichten bilden (Webster und Aström 2009; Kaplan et al. 1997). Dabei werden die inneren Schichten als kompaktes Myelin bezeichnet, da der Zwischenraum nur $2 \mathrm{~nm}$ dick ist, in den äußeren, nicht-kompakten Schichten beträgt der Extrazellularraum 12-14 nm (Kursula 2008).

Die Myelinscheide besteht zu etwa $15-30 \%$ aus Proteinen, die Hauptmasse bilden Lipide, deren Zusammensetzung sich nicht wesentlich von der der Schwannzellen im peripheren Nervensystem unterscheidet. Einen großen Proteinanteil bildet mit $30-40 \%$ das Myelinbasische Protein (MBP), wovon 6 Isoformen in den Größen 14 - 21,5 kDa bekannt sind, wobei die Isoform 18,5 kDa die häufigste ist (Takahashi et al. 1985, Newman et al. 1987). Durch seine basischen Komponenten kann dieses Protein durch Wechselwirkung mit sauren Proteingruppen die lamelläre Struktur der Myelinscheide aufrechterhalten (Hauraz et al. 2009, Omlin et al. 1982). MBP kommt auch im PNS vor, jedoch zu geringerem Anteil. Spezifisch im ZNS weist das dicht gepackte Myelin sog. Okklusionsleisten auf, auch radiale 
Komponenten genannt. Diese Verbindung der einzelnen Membranen besteht ebenfalls aus dem Myelin- assoziierten Oligodendrozyten- basischen Protein (MOBP), welches insgesamt ca. 4\% Anteil am Gesamteiweiß des Myelins hat. Weitere Proteinkomponenten sind das Proteolipidprotein (PLP), ein Membranprotein, das etwa 50\% der Myelinproteine ausmacht und auch im PNS vorkommt. Das 100 kDa große Myelin-assoziierte Glykoprotein (MAG) ist ebenfalls ein auch im PNS vorkommendes Transmembranprotein mit einer zytoplasmatischen Komponente. Oligodendrozyten-Myelin-Glykoprotein (OMGP) ist ein $120 \mathrm{kDa}$ großes, spezifisch im ZNS lokalisiertes Glykoprotein. Desweiteren kommen vor die 2',3'-zyklische Nukleotid-3-Phosphodiesterase mit 4\%, das Oligodendrozytenspezifische Protein und das Myelin- Oligodendrozyten- Glykoprotein (MOG). MOG macht zwar nur etwa $0,1 \%$ des Gesamtproteinanteils im Myelin aus, ist aber hochspezifisch für das ZNS und trägt einen extrazellulären Anteil auf der äußersten Myelinmembran, welcher durch seine Lage als bevorzugtes Ziel einer Immunreaktion in Frage kommt (Klawiter et al. 2010, Della Gaspera et al. 1998). So kann zum Beispiel die Demyelinisierung bei EAE, einer der MS entsprechenden Erkrankung am Tiermodell, bei Mäusen durch die Injektion eines Anti-MOG-AK gesteigert werden (Lyons et al. 2002). Des weiteren wurden Antikörper gegen dieses Myelinprotein in aktiven Läsionen nachgewiesen (Genain et al. 1999, Raine et al. 1999). MOG ist ein Dimer aus einem 24- und einem 28 kDa großen Fragment, als dessen Funktion die eines Adhäsions- oder Rezeptormoleküls angenommen wird (Linington et al. 1988, Amiguet 1992, Clements et al. 2003).

Antikörper gegen MOG mit seiner anteilig extrazellulären Lage und gegen MBP mit seinem hohen Gesamtanteil am Myelin sind Inhalt der hier vorgestellten Arbeit.

\subsection{Die frühe Multiple Sklerose}

Im Zuge der Erstmanifestation, in den meisten Fällen als sogenanntes klinisch isoliertes Syndrom (CIS), werden als häufigste Ausfallerscheinungen Sensibilitätsstörungen, Paresen, Ataxie oder Störungen der Sehfunktion angegeben (Gold und Rieckmann 2004).

In den letzten Jahren ist aufgrund der immer besser werdenden bildmorphologischen Darstellungen mittels MRT die radiologische Diagnostik immer mehr in den Fokus gerückt. Eine neue mögliche Erstmanifestation der MS im noch subklinischen Stadium wurde als 
radiologisch isoliertes Syndrom (RIS) definiert, wobei genaue Kriterien bezüglich der Form und Intensität zerebraler oder zervikaler Herde, der Wichtung des pathologischen MRTs, des Fehlens entsprechender klinischer Neurologie und des Ausschlusses anderer Ursachen für die Läsionen wie zum Beispiel Drogenabusus oder andere Erkrankungen erfüllt sein müssen (Okuda et al. 2009, Sellner et al. 2010). Als prädiktive Faktoren für die Entwicklung einer MS nach RIS haben sich neben jungem Alter des Patienten die Gadoliniumaufnahme der Läsionen, eine Thalamusatrophie, das Vorliegen zervikaler Herde und eine Vergrößerung der Ventrikel herausgestellt (Zivadinov et al. 2013, Okuda et al. 2009). Ausserdem kommen pathologische Untersuchungsergebnisse visuell evozierter Potentiale sowie der Nachweis oligoklonaler Banden im Liquor bei späteren MS-Patienten häufiger vor als bei RIS ohne nachfolgende Symptomatik (Lebrun et al. 2009). Nach inzidentellem Auftreten eines RIS entwickelt sich innerhalb von 2 Jahren bei etwas über einem Drittel der Patienten ein CIS, womit mittels radiologischem Nachweis örtlicher und zeitlicher Dissemination oft bereits die Diagnose MS gestellt werden kann (Lebrun et al. 2009, Okuda et al. 2009, Siva et al. 2009). Im Vergleich wird nach einem CIS bei circa 70\% der Patienten im Verlauf eine Multiple Sklerose diagnostiziert.

Unsicher ist jedoch noch immer eine individuelle Voraussage über die Entwicklung einer manifesten MS nach Auftreten eines CIS. Hierbei gilt ein pathologisches MRT als relativ sicherer prädiktiver Faktor für den Übergang in eine manifeste Erkrankung. Weniger sicher sind dagegen auffällige Liquorbefunde und abnormale evozierte Potentiale (Marcus und Waubant 2013, Rieckmann 2005).

Das Vorkommen der Anti-Myelin-Antikörper gegen MOG und gegen MBP im Serum von CIS-Patienten wurde als positiver prädiktiver Faktor postuliert. Bis heute sind zu diesem Thema zahlreiche, z.T. widersprüchliche Studien veröffentlicht worden (s. Kapitel 2.4).

Moderne Studien fokussieren häufig auf CIS-Patienten, um immer sicherere und frühere Möglichkeiten zur Diagnose einer MS und damit zur Indikation einer Therapie zu finden (z.B. Kappos et al. 2006 und 2007, Jacobs et al. 2000). Es werden hierbei vor allem weitere prädestinierende Faktoren wie pathologische Befunde im MRT, in der Elektrophysiologie, im Liquor oder, wie in der vorliegenden Studie, im Blut gesucht. Das Vorkommen von Antikörpern gegen MOG und MBP in Liquor oder Serum gilt bisher noch nicht als Faktor 
für die Stellung einer Prognose nach einem CIS, der Beweis gegen deren prädiktive Bedeutung konnte bisher jedoch ebenfalls nicht geführt werden. (Xu et al. 2012, Klawiter et al. 2010).

Unumstritten ist der Nutzen eines möglichst frühzeitigen Therapiebeginns (Comi 2003, Tintoré 2008, Sellner et al. 2010). Da die MS ein Fortschreiten und letztendlich eine Akkumulation neurologischer Schäden darstellt, ist eine frühe Eindämmung der Immunreaktion vor dem Auftreten irreversibler Störungen von höchster Wichtigkeit. Große prospektive Studien wie die CHAMPS/CHAMPIONS-, die ETOMS-, die BENEFIT- und die PRECISE-Studie haben in den letzten Jahren einen positiven Effekt früher Therapien herausgearbeitet (Kinkel et al. 2012, Filippi et al. 2004, Kappos et al. 2007, Comi et al. 2009). Nach einer klinischen Studie konnte durch Frühtherapie sogar eine Risikoreduktion für eine CDMS nach CIS von 38-68\% auf 44-50\% erreicht werden (Kohriyama 2011).

Umso wichtiger wird die Erforschung möglicher Parameter zur Frühdiagnostik, so dass das therapeutische Vorgehen in Zukunft möglicherweise schon nach Auftreten eines CIS oder sogar bereits nach einem RIS festgesetzt werden kann.

\subsection{Aktuelle Studienlage}

In den letzten Jahren wurden die Forschungsergebnisse der Gruppe um Berger, in der ein prädiktiver Wert für die Entwicklung einer MS der Antikörper gegen MBP und MOG gezeigt wurde, durch zahlreiche verschiedene Gruppen, unter anderem auch von der BergerGruppe selbst, mit unterschiedlichen Methoden sowohl bestätigt als auch widerlegt.

Im Jahr 2003 wurde von Berger et al. die bereits erwähnte Studie über den prädiktiven Wert von Anti-MOG-AK für die Entwicklung einer sicheren MS nach Auftreten eines CIS publiziert. In dieser Studie konnte belegt werden, dass die Patienten, bei denen zum Zeitpunkt des CIS diese AK nachweisbar waren, signifikant öfter eine MS entwickelten als die Patienten ohne AK. Die AK wurden mittels Western Blot detektiert, die Methodik sowie die Materialien wurden zur optimalen Vergleichbarkeit der Ergebnisse für die vorliegende Arbeit übernommen.

2004 bestätigten Gaertner et al. mittels ELISA das erhöhte Vorkommen von Anti-MOG-AK in Patienten mit MS. Zahlreiche Arbeitsgruppen kamen mit verschiedenen Methoden zu 
ähnlichen Ergebnissen (Greeve et al. 2007; Lalive et al. 2006; Tomassini et al. 2007). Ebenfalls im Jahr 2004 wurde von Lampasona et al. im Vergleich mit gesunden Kontrollpersonen über einen Radioimmunassay kein höherer AK-Titer von Anti-MOG-AK bei MS-Patienten gefunden. Auch diese Widerlegung wurde durch mehrere Arbeitsgruppen mit unterschiedlichen Methoden sowohl für MS- als auch für CIS-Patienten bestätigt (Kuhle et al. 2007, Lim et al. 2005).

Eine Zusammenschau der verschiedenen Ergebnisse lässt einen Zusammenhang mit der verwandten AK-Detektionsmethode vermuten, daneben spielen unterschiedliche Patientenpopulationen vermutlich ebenfalls eine Rolle.

In anderen Studien stand die Frage nach der Spezifität der pathologischen Antikörper für spezielle Domänen des Proteins bzw. für die natürliche Tertiärstruktur des Proteins MOG im Mittelpunkt (Chan et al. 2010; Khalil et al. 2006, Menge et al. 2005). Über FACS-Analysen wurde bei pädiatrischen MS-Patienten ein signifikant erhöhter Titer von Anti-MOG-AK gefunden (McLaughlin et al. 2009). Auch für die der MS ähnliche Erkrankung, die NMO, wurde ein Zusammenhang mit Anti-MOG-Antikörpern innerhalb einer Subgruppe gezeigt (Mader et al. 2012). Auch hier wurde mittels FACS-Analysen gearbeitet.

Es wurde postuliert, dass lediglich die Antikörper gegen das Protein in seiner natürlichen Konformation pathologisches Potential besitzen. Auch diese These wurde im Verlauf widerlegt wie auch bestätigt. Ein Studiendesign von Menge et al. 2011 sah die Untersuchung von Seren gesunder Spender, CIS-Patienten und CDMS-Patienten mit 3 verschiedenen rekombinanten Varianten des Proteins MOG vor. Dabei wurden auch die Reaktionen mit dem natürlich konformierten, einem zum Teil denaturierten und einem vollständig denaturierten Protein verglichen. Hier zeigte sich zum einen eine abnehmende Antikörperkonzentration mit der Denaturierung und zum anderen eine Konkordanz des Antikörpervorkommens mit der Krankheitsaktivität (Menge et al. 2011).

Bezüglich des MBP wurden Antikörper gegen bestimmte Fragmente des Proteins bei MSPatienten im Vergleich zu gesunden Probanden in deutlich höheren Konzentrationen gefunden (Belogurov et al. 2008). Ein sicherer und reproduzierbarer Beweis für den prädiktiven Wert der Antikörper gegen MOG und MBP bezüglich der Krankheitsentwicklung steht bis heute aus. 


\subsection{Fragestellung}

Die vorliegende Arbeit beschäftigt sich nicht nur mit der Rolle, sondern auch mit dem Zeitpunkt des Auftretens von Antikörpern gegen Myelin-Oligodendrozyten-Glykoprotein (MOG) und basisches Myelinprotein (MBP).

Das langfristige Ziel ist die Auffindung von sicheren und möglichst früh erfassbaren paraklinischen Markern zur Frühdiagnostik der MS. Dies wird immer wichtiger, nachdem der Nutzen einer frühen Therapieeinleitung in mehreren Studien bewiesen wurde. Auch eine von Beginn an bessere Einschätzung der Prognose und somit eine nicht nur schnellere, sondern auch gezieltere und damit effizientere Therapieeinleitung könnte hiermit ermöglicht werden. Antikörper im Serum wären als einfach nachzuweisender Parameter ein idealer Marker zur Einordnung eines Patienten in die Kategorie "therapiebedürftig" oder eher hin zu einer abwartenden Haltung (Coyle 2008, Comi 2003, Tintoré 2008, Sellner et al. 2010). Durch die Untersuchung von Serumproben, welche noch vor dem Auftreten eines CIS abgenommen wurden und später auch die Auswertung derselben Patienten nach Diagnose einer CDMS, sollte nicht nur ein spezifischer Antikörper detektiert, sondern auch dessen zeitlicher Zusammenhang mit der MS herausgearbeitet werden. Dieses frühe Stadium noch vor Auftreten der ersten Krankheitssymptome ist bisher noch nicht eingehend untersucht worden. So ist der Anfangszeitpunkt der pathogenetischen Kaskade vor Ausbruch der Krankheit bisher noch unklar. 


\section{Material und Methoden}

\subsection{Material}

\section{Geräte}

Elektrophoresekammer Protean 3 Cell

Trans-Blot SD

Spannungsgeber

Gel-Blotting-Papier

Nitrocellulose Transfermembran

Sterilbank Hera Safe

Stickstofftank

"Mr Frosty" Freezing Container

Kryotubes

Mikroskop

Weitere Laborartikel
Bio-Rad, Hercules, USA

Bio-Rad, Hercules, USA

Bio-Rad, Hercules, USA

Schleicher + Schuell, Dassel, BRD

Whatman GmbH, Dassel, BRD

Heraeus, Hanau, BRD

Taylor Wharton, Mildstedt, BRD

Nalgene Labware, Roskilde, DEN

Nunc, Langenselbold, BRD

Zeiss, Oberkochen, BRD

Eppendorf, Hamburg und Hartenstein, BRD

\section{Antikörper und Sekundärantikörper}

Anti-MOG 8-18-C5

Anti-MBP MAB381

Mouse-anti-human-IgG, AP-gekoppelt

(Sekundärantikörper)

Mouse-anti-human-IgM, AP-gekoppelt

(Sekundärantikörper)
Zur Verfügung gestellt von Prof. Dr. T.

Berger, Innsbruck, AU

Zur Verfügung gestellt von Prof. Dr. T.

Berger, Innsbruck, AU

Zur Verfügung gestellt von Prof. Dr. T.

Berger, Innsbruck, AU

Zur Verfügung gestellt von Prof. Dr. T.

Berger, Innsbruck, AU

\section{Reagenzien}

Molekulargewichtsstandard

Färbe-Kit mit alkalischer Phosphatase

Acrylamidmix

Tris(hydroxymethyl)-aminomethan (TRIS)

Sodium Dodecyl Sulfat (SDS)
Bio-Rad, Hercules, USA

Bio-Rad, Hercules, USA

Roth, Karlsruhe, BRD

Roth, Karlsruhe, BRD

Roth, Karlsruhe, BRD 
Molekulargewichtsstandard

Färbe-Kit mit alkalischer Phosphatase

Tetramethylethylendiamin (TEMED)

Ammoniumpersulfat (APS)

Glycerin

Beta-Mercaptoethanol

Bromphenolblau

Glycin

Polysorbate 20 (TWEEN)

Methanol

Trypanblau

FCS

Dimethylsulfoxid

Trypsin EDTA

L-Glutamin

Na-Pyuvat

Dinatriumhydrogenphosphat

Na-Dihydrogenphosphat

Natriumazid

Kaliumchlorid

Natriumchlorid
Bio-Rad, Hercules, USA

Bio-Rad, Hercules, USA

Roth, Karlsruhe, BRD

Roth, Karlsruhe, BRD

Roth, Karlsruhe, BRD

Roth, Karlsruhe, BRD

Roth, Karlsruhe, BRD

Roth, Karlsruhe, BRD

Roth, Karlsruhe, BRD

Roth, Karlsruhe, BRD

Merck, Daredtadt, BRD

PAA, Cölbe, BRD

Roth, Karlsruhe, BRD

Gibco, Karlsruhe, BRD

Gibco, Karlsruhe, BRD

Gibco, Karlsruhe, BRD

Roth, Karlsruhe, BRD

Roth, Karlsruhe, BRD

Roth, Karlsruhe, BRD

Roth, Karlsruhe, BRD

Roth, Karlsruhe, BRD 
Tris 0,1M pH 9,5

$6,057 \mathrm{~g}$ TRIS

$500 \mathrm{ml} \mathrm{NaCl}$

Tris 1,5M pH 8,8

$18,53 \mathrm{~g}$ TRIS

$100 \mathrm{ml} \mathrm{NaCl}$

APS 10\%

$0,5 \mathrm{~g}$ APS

$5 \mathrm{ml}$ Aqua dest.

\section{Laufpuffer}

100g Glycin

$15 \mathrm{~g}$ TRIS

$5 \mathrm{~g}$ SDS

11 Aqua dest.

Probenpuffer

$6,25 \mathrm{ml}$ Tris $1 \mathrm{M}$

$8 \mathrm{~g}$ SDS

$15 \mathrm{ml}$ Glycerin

$3 \mathrm{ml}$ beta-Mercaptoethanol

75,75ml Aqua dest.

1 Spatelspitze Bromphenolblau

\section{Trenngel (15\%)}

3,4ml Aqua dest.

7,5ml Acrylamidmix

$3,8 \mathrm{ml}$ Tris $1,5 \mathrm{M}$

$150 \mu \mathrm{l}$ SDS $10 \%$

$150 \mu 1$ APS $10 \%$

$6 \mu 1$ TEMED

\section{Sammelgel (5\%)}

5,5ml Aqua dest.

1,2ml Acrylamidmix

$1 \mathrm{ml}$ Tris $1 \mathrm{M}$

$80 \mu 1$ SDS $10 \%$

$80 \mu \mathrm{l}$ APS 10\%

$8 \mu 1 \mathrm{TEMED}$
Tris 1 M pH6,9

$12,114 \mathrm{~g}$ TRIS

$100 \mathrm{ml} \mathrm{NaCl}$

Tris $2 \mathrm{M} \mathrm{pH} \mathrm{6,8}$

24,228g TRIS

$100 \mathrm{ml} \mathrm{NaCl}$

SDS 10\%

$10 \mathrm{~g}$ SDS

$10 \mathrm{ml}$ Aqua dest.

Western-Blot-Puffer

14,4g Glycin

$3 \mathrm{~g}$ TRIS

$100 \mathrm{ml}$ Aqua dest.

Blot-Puffer

20ml Western-Blot-Puffer

40ml Methanol

140ml Aqua dest.

Waschpuffer

11 TBS

$1 \mathrm{ml}$ Tween

TBS (1x)

Ein Liter Lösung:

50mmol/1 TRIS

$150 \mathrm{mmol} / 1 \mathrm{NaCl}$

PBS (10x)

Ein Liter Lösung:

1,369mol/1 NaCl

100mmol/1 Dinatriumhydrogenphosphat

100mmol/1 Na-Dihydrogenphosphat

$27 \mathrm{mmol} / 1$ Kaliumchlorid 


\subsection{Probensammlung}

Die Untersuchungen wurden von der Ethikkommission der Medizinischen Fakultät der Georg-August-Universität Göttingen genehmigt.

Zur Realisierung einer retrospektiven Untersuchung von Serumparametern wurde die im deutschen Transfusionsgesetz (Vierter Abschnitt, Paragraph 19) geforderte Rückverfolgbarkeit von Blutspenden genutzt. Dieses verlangt zur Möglichkeit einer Rückverfolgung bei Infektionsnachweis die Aufbewahrung von Proben jedes Spenders für einen angemessenen Zeitraum, welcher von den jeweiligen Instituten selbst bestimmt und in den von uns kontaktierten zwischen 3 und 15 Jahren liegt.

Zur Patientenrekrutierung wurde auf der Internetseite der Deutschen Multiple Sklerose Gesellschaft ein Aufruf an alle Patienten gestartet, die vor Ausbruch ihrer Erkrankung Blut gespendet hatten. Die jeweiligen Transfusionsmedizinischen Institute stellten uns die Rückstellproben nach Ablauf der Aufbewahrungsfrist zur Verfügung.

Anschließend wurden nach Erhalt einer Einverständniserklärung der Patienten von den behandelnden Ärzten oder Kliniken die jeweiligen Arztbriefe aus der Zeit der Erstdiagnose angefordert.

Zuletzt wurden die Patienten gebeten, zur Verlaufsbeobachtung erneut eine Serumprobe abzugeben.

Insgesamt standen uns 81 Proben von 37 Patienten zur Verfügung. Ausschlusskriterien stellten ein nachgewiesenes CIS vor der Blutspende und eine nicht sicher zu diagnostizierende MS dar. Hierdurch wurden nach Erhalt der klinischen Daten 8 Patienten nachträglich ausgeschlossen. Zur Auswertung standen 61 Proben verschiedenen Spendedatums von 25 Patienten im Alter von 18 bis 45 Jahren (bei Abnahme der Blutspende), davon 5 männlich und 20 weiblich. Die Spenden erfolgten zwischen 2 Monaten und 7 Jahren vor Auftreten der Erstsymptome. Eine aktuelle Blutprobe von 2007 konnten uns 19 Patienten zukommen lassen.

Alle Proben wurden bei $-80^{\circ} \mathrm{C}$ aliquotiert in $100 \mu 1$ gelagert, die Versendung erfolgte, wenn möglich, gefroren auf Trockeneis, dabei erhielten wir 43 der erhaltenen Proben von 15 Patienten nach dem Versand in aufgetautem und die übrigen 18 Proben von 10 Patienten in 
gefrorenem Zustand. 35 Proben von 12 Patienten lagen als Plasma vor, 26 Proben von 13 Patienten als Serum. (s. Tab.1)

Die Kontrollseren stammen mit freundlicher Unterstützung von PD Dr. Riggert aus der Abteilung Transfusionsmedizin der Universitätsmedizin Göttingen und mit dem Einverständnis der Blutspender aus den an einem Tag gespendeten Proben des Blutspendedienstes der Universität Göttingen. Die Auswahl aus dem Gesamtkollektiv erfolgte unter Berücksichtigung von Alter und Geschlecht. (s.Tab.1)

\begin{tabular}{|c|c|c|}
\cline { 2 - 3 } \multicolumn{1}{c|}{} & Patienten $\mathrm{n}=25$ & Kontrollen $\mathrm{n}=25$ \\
\hline Alter (Median) & $18-44(30)$ & $18-44(30)$ \\
\hline Geschlecht $\mathrm{m} / \mathrm{w}$ & $5 / 20$ & $5 / 20$ \\
\hline Serum/Plasma & $13 / 12$ & $25 / 0$ \\
\hline Volumen & $100 \mu \mathrm{l}-1,2 \mathrm{ml}$ & $300-500 \mu \mathrm{l}$ \\
\hline
\end{tabular}

Tab.1: Patienten- und Kontrollkollektiv

\subsection{Western Blot}

Der Western Blot ist ein Verfahren zum Nachweis von immobilisierten, im allgemeinen denaturierten Proteinen unter Verwendung spezifischer Antikörper. Im folgenden Versuchsaufbau wurde unter Verwendung spezieller bekannter Antigene (MOG und MBP) das Auftreten von Antikörpern in Serumproben nachgewiesen.

\section{Diskoninuierliche SDS-Gelelektrophorese}

Vor dem Zusammenbau der Gießkammer wurden alle mit den Gelen in Kontakt kommenden Teile mit einem ethanolgetränkten, fusselfreien Tuch entfettet. Es wurden gleichzeitig ein 15\%iges Trenn- und ein 5\%iges Sammelgel für das Volumen von zwei Kammern angesetzt. Hierbei wurde die Porengröße des Sammelgels größer als die des Trenngels gewählt, so dass die Proteine im Trenngel als scharfe Bande aufliegen und gemäß ihrer Größe das Trenngel durchlaufen. Das Trenngel wurde luftblasenfrei bis $7 \mathrm{~mm}$ unter den Rand der kleineren Platten gegossen, danach wurde bis zu den Oberkanten mit dem Sammelgel aufgefüllt. Noch in flüssigem Gelzustand wurden vorsichtig die Taschenformer eingesetzt. Nach vollständiger Polymerisation innerhalb von 1h konnten die Glasplatten in 
die Laufkammer eingespannt und die Taschenformer entfernt werden. Die Laufkammer wurde bis zum oberen Rand der Platten mit alkalischem Laufpuffer gefüllt, um die negative Ladung der Proteine zu gewährleisten.

Die verwandten Antigene MBP (human) und MOG (aa1-125) lagerten aliquotiert zu $2 \mu \mathrm{g}$ und $1 \mu \mathrm{g}$ in einer Konzentration von $1,5 \mathrm{mg} / \mathrm{ml}$ für MBP und $1,4 \mathrm{mg} / \mathrm{ml}$ für MOG bei $-80^{\circ} \mathrm{C}$, wobei MBP in Aqua dest. und MOG in Säure (pH 3,3) gelöst vorlagen (Berger et al. 2003). Kurz vor dem Start der Elektrophorese wurden $100 \mu 1$ Aqua dest. und $40 \mu 1$ Probenpuffer zugefügt. Dieser enthält zur Denaturierung der Proteine beta-Mercaptoethanol. Zum pHAusgleich der MOG-Lösung wurden hier $5 \mu 12 \mathrm{M}$ Tris mit einem $\mathrm{pH}$ von 6,8 zugegeben. Anschliessend wurden die Gemische zentrifugiert (90sec, $125 \mathrm{rpm}$ ) und $5 \mathrm{~min}$ bei $98^{\circ} \mathrm{C}$ gekocht. Die großen Taschen der beiden Gele wurden mit je einem Antigen beladen, in die kleinen Taschen wurden zur Identifizierung der Banden je $5 \mu 1$ des Molekulargewichtsstandards gegeben. Mit dem Anschluß des Systems an eine Stromstärke von 40mA und einer Spannung von 140V wurde die Elektrophorese gestartet. 10 min nach dem Herauslaufen der mit Bromphenolblau sichtbar gemachten Proteinbanden wurde der Lauf beendet, in der Regel nach 65-75min. So konnte eine exakte Bestimmung sowie die benötigte Reinheit der 15 und 18,5 kDa großen Antigene gewährleistet werden. Die Gele wurden von den Glasplatten genommen und zum Schutz vor Aushärtung vorübergehend in Blot-Puffer gelegt.

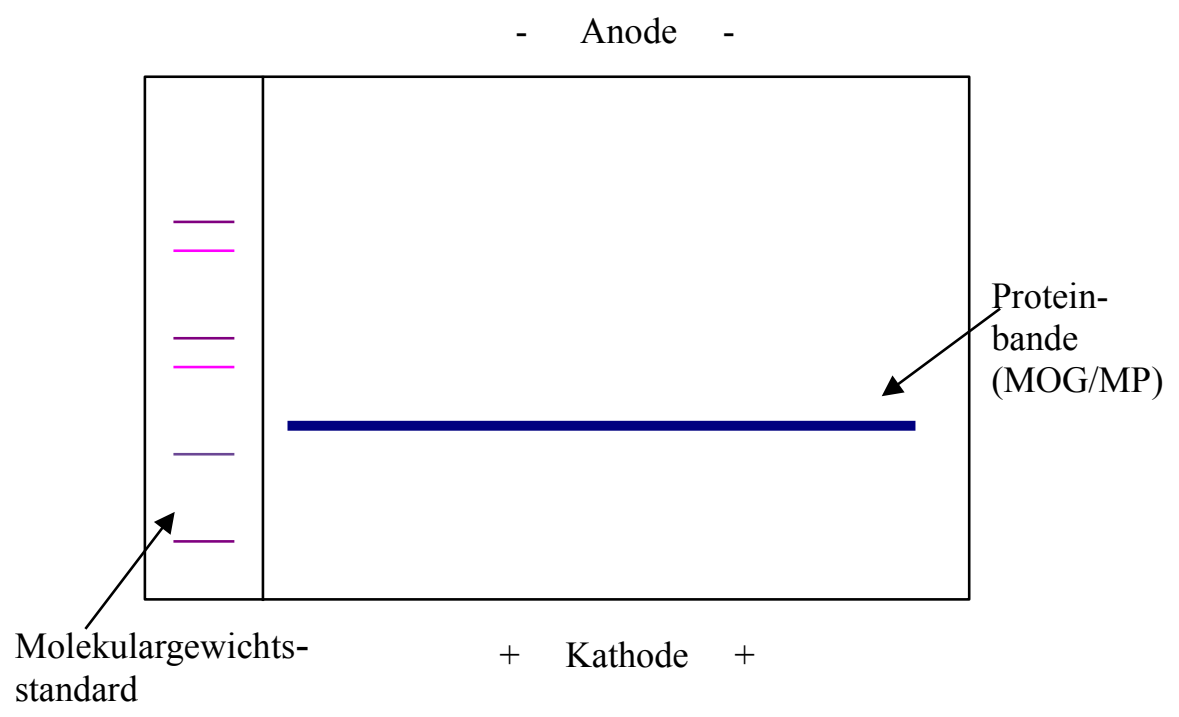

Abb.1 Gelelektrophorese schematisch 


\section{Western Blot im semi-dry Verfahren}

Für den Transfer der Antigene auf die Membran per Sandwichverfahren wurden zunächst vier $18 \times 8,5 \mathrm{~cm}$ große Filterpapiere und die gleich große Nitrozellulosemembran mit einer

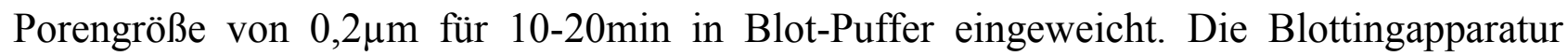
wurde ebenfalls mit dem Puffer angefeuchtet. Die untere Platte wurde später als Anode geschaltet, die obere als Kathode. Auf die Anodenplatte wurden zwei der Filterpapiere und die Membran gelegt, die beiden Gele wurden auf der Membran spiegelverkehrt gegenüber plaziert und mit den beiden restlichen Filterpapieren abgedeckt (Abb.2).

Zur klaren Kennzeichnung der mit unterschiedlichen Proteinen versetzten Gele wurde die Membran immer an der linken oberen Ecke angeschnitten. Nachdem Luftblasen und überschüssiger Puffer entfernt waren, erfolgte der Transfer über 43min bei einer Stromstärke von 200mA. Der Puffer enthielt hierbei Methanol, um die SDS-Bindung der Antigene zu lösen und somit deren Bindung an die Membran zu verbessern.

Zur Kontrolle wurden die Proteinbanden durch 5-minütige Inkubation mit PonceauS sichtbar gemacht. Der Molekulargewichtsstandard wurde mit einem Skalpell abgetrennt und zwischen zwei Filterpapieren getrocknet.

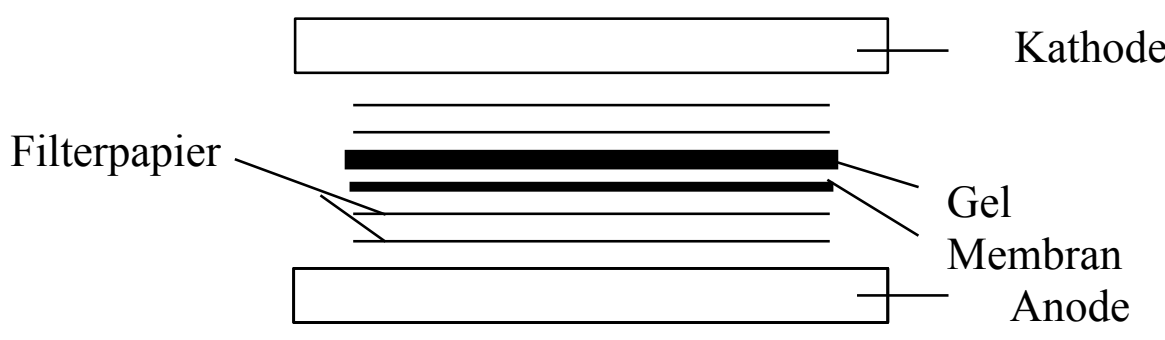

Abb.2 Proteintransfer auf eine Membran mittels Elektrophorese

Aus der Nitrozellulose wurden mit dem Skalpell 3mm große Streifen so geschnitten, dass auf einer Seite das MOG, auf der anderen Seite das MBP gebunden waren und diese 3 x 5 min mit je $3 \mathrm{ml}$ Waschpuffer gewaschen. Anschliessend wurden unspezifische Bindungsstellen mit der Blocklösung geblockt. Nach 1,5 h wurde die Blocklösung abgeschüttet, die Schalen mit den einzelnen Seren bestückt und über Nacht bei $4^{\circ} \mathrm{C}$ inkubiert. 


\section{Vorbereitung der Seren und der Kontrollantikörper}

Zur Versuchskontrolle dienten der von Prof. Th. Berger aus Innsbruck zur Verfügung gestellte monoklonale Maus-Antikörper 8-18-C5 gegen MOG (Berger et al. 2003) und MAB381, Isotyp IgG1, gegen MBP (Chemicon). Beide Antikörper lagen in einer Vorverdünnung von 1:100 vor und wurden in den Titrationsstufen 1:32 000, 1:64 000, 1:128 000, 1:256 000 und 1:512 000 mit der Blocklösung vermischt (Abb.3).

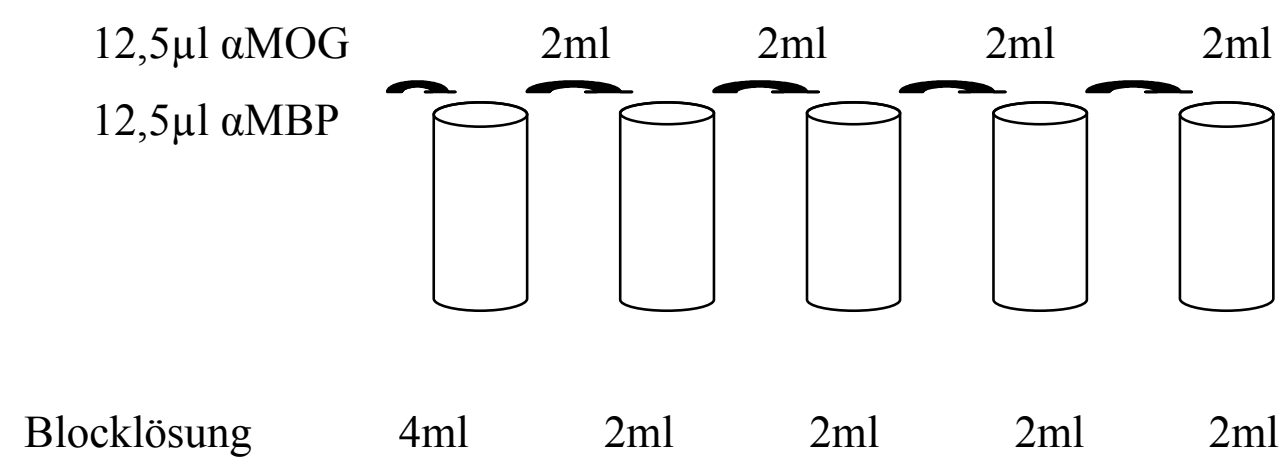

Abb.3 Verdünnung der Mäuse- Kontrollseren

Als humane Kontrolle wurde ein von PD Dr. A. Weishaupt, Neurologische Universitätsklinik Würzburg, für beide Antikörper positiv getestetes Patientenserum verwendet. Beruhend auf vorangegangene Untersuchungen wurden für den IgG-Nachweis die Konzentrationen 1:1000 und 1:500 gewählt, für die IgM-Kontrolle 1:2000 und 1:500. Die Patientenseren wurden für IgG in der Konzentration 1:1000 und für IgM in der Konzentration 1:500 mit der Blocklösung gemischt.

\section{Visualisierung der Antikörper}

Nach mehrmaligem Waschen mit TBS-Tween $(1 \times 1 \mathrm{~min} ; 3$ x $12 \mathrm{~min})$ wurden die APgekoppelten Sekundärantikörper Anti-Maus-, Anti-IgG- und Anti-IgM in einer Endverdünnung von 1:5000 auf die entsprechenden Streifen aufgebracht. Es folgte eine Inkubation über $1 \mathrm{~h}$ und erneutes Waschen mit Waschpuffer sowie mit $0,1 \mathrm{M}$ Tris zum $\mathrm{pH}$ Ausgleich. Der Entwicklungspuffer wurde im Verhältnis 1:25 mit Aqua dest. gemischt und die Färbereagenzien A und B in der Konzentration $100 \mu 1 / 10 \mathrm{ml}$ hinzugefügt. Es folgte die 
Inkubation über 20min. Die Farbreaktion entsteht bei der verwendeten Technik durch die katalytische Aktivität der Alkalischen Phosphatase, welche das im Färbereagenz B enthaltene BCIP dephosphoryliert und so den Farbumschlag von schwach gelb zu blau induziert. Das im Reagenz A gelöste NBT wird gleichzeitig reduziert und zeigt in dieser Form eine violette Färbung. Alle Proteinbanden mit gebundenem Sekundärantikörper erhielten nach der Färbung eine blau-violette Tönung.

Nach abschliessender Waschung mit Aqua dest. für 3 x 5 min wurden die Nitrozellulosestreifen zwischen Whatmanpapier getrocknet und zur Auswertung auf Papier geklebt.

\subsection{Statistische Auswertung}

Im Programm Graph pad prism wurde die Signifikanz mittels Students-t-Test errechnet. Für die Ergebnisse des Western Blot wurde das Vorkommen von Antikörpern in Prozent ermittelt.

\subsection{Klinische Auswertung}

Zur klinischen Auswertung des Patientenkollektivs wurden Alter, Geschlecht, Zeitpunkt der Blutspende in Bezug auf das CIS, die Erstsymptomatik und der EDSS nach dem CIS herangezogen.

EDSS bezeichnet den durch die MS hervorgerufenen Behinderungsgrad und bezieht sich auf die Anzahl und Ausprägung der Schädigung der betroffenen Funktionssysteme (Kurtzke 1983) (s. Tab.2). Im Gegensatz zur veralteten Version, der DSS, werden hier Behinderungen im Alltag und Einschränkungen der Mobilität mit berücksichtigt. 


\begin{tabular}{|c|c|}
\hline EDSS & Befund \\
\hline 0 & normaler neurologischer Untersuchungsbefund \\
\hline 1 & keine Behinderung, milde Symptomatik in einem funktionellen System \\
\hline 1,5 & keine Behinderung, milde Symptomatik in mehr als einem funktionellen System \\
\hline 2 & leichte Behinderung in einem funktionellen System \\
\hline 2,5 & leichte Behinderung in mehr als einem funktionellen System \\
\hline 3 & $\begin{array}{c}\text { deutliche Behinderung in einem funktionellen Systemoder leichte Behinderung in drei oder vier funktionellen Systemen, } \\
\text { Gehfähigkeit erhalten }\end{array}$ \\
\hline 3,5 & $\begin{array}{l}\text { deutliche Behinderung in zwei funktionellen Systemen oder in einem funktionellen System mit leichter Symptomatik in einemoder } \\
\text { zwei funktionellen Systemen oder leichte Behinderung in fünf funktionellen Systemen, Gehfähigkeit erhalten }\end{array}$ \\
\hline 4 & Gehfähigkeit ohne Hilfe und Ruhepause mind. $500 \mathrm{~m}$; tägliche Aktivität von $12 \mathrm{~h}$ möglich, relativ schwere Behinderung \\
\hline 4,5 & $\begin{array}{c}\text { Gehfähigkeit ohne Hilfe und Ruhepause mind. } 300 \text { m; ganztägig arbeits fähig, Aktivitätseinschränkungen, relativ schwere } \\
\text { Behinderung }\end{array}$ \\
\hline 5 & Gehfähigkeit ohne Hilfe und Ruhepause für etwa 200 m; tägliche Aktivitäten von schwerer Behinderung beeinträchtigt \\
\hline 5,5 & Gehfähigkeit ohne Hilfe und Ruhepause für etwa $100 \mathrm{~m}$; keine normale tägliche Aktivitätmehr möglich bei schwerer Behinderung \\
\hline 6 & Gehfähigkeit mit einseitiger oder zeitweiliger Unterstützung (Gehhilfe) ohne Ruhepause für etwa $100 \mathrm{~m}$ \\
\hline 6,5 & Gehfähigkeit mit andauernder, beidseitiger Unterstützung (Gehhilfe) ohne Ruhepause für etwa $20 \mathrm{~m}$ \\
\hline 7 & $\begin{array}{l}\text { unfähig, selbst mit Hilfe, mehr als } 5 \mathrm{mzu} \text { gehen; weitgehend rollstuhlbedürftig, dabei aber selbständig und aktiv, Transfer ohne } \\
\text { Hilfe }\end{array}$ \\
\hline 7,5 & unfähig, mehr als ein paar Schritte zu gehen; rollstuhlbedürftig, Hilfe bei Benutzung und Transfer benötigt, evtl. E-Rollstuhl \\
\hline 8 & weitgehend auf das Bett beschränkt, fähig im Rollstuhl zu sitzen,selbständige Körperpflege mit meist gutem Gebrauch der Arme \\
\hline 8,5 & weitgehend auf das Bett beschränkt, fähig im Rollstuhl zu sitzen, teilweise selbständige Pflege mit teilweisem Gebrauch der Arme \\
\hline 9 & hilflose Bettlägerigkeit, Nahrungsaufnahme und Kommunikationsvermögen erhalten \\
\hline 9,5 & völlige Hilflosigkeit mit gestörter Nahrungsaufnahme (Schluckstörungen) und Kommunikation \\
\hline 10 & Tod durch MS \\
\hline
\end{tabular}

Tab.2: Extended Disability Status Scale 


\section{Ergebnisse}

Die Proben wurden jeweils auf IgG- und IgM-Antikörper gegen die Myelinproteine MOG und MBP getestet. Bei der Auswertung wurde zwischen diesen 4 Antikörpern, dem völligen Fehlen der getesteten Antikörper und dem Vorkommen von sowohl Anti-MOG als auch Anti-MBP unterschieden.

Insgesamt wurde ein Lauf zur Auswertung gegeben, wenn sowohl die Banden der Mauskontrollen sowie die der humanen Positivkontrolle scharf zu erkennen waren.

Die Proben wurden im Vergleich $\mathrm{zu}$ den in absteigenden Konzentrationen verwandten Maus-Kontrollseren betrachtet. In die Kategorie "positiv" wurden Banden eingestuft, deren Farbintensität den Konzentrationen 1: 32000 und 1: 64000 entsprachen. (Abb.4)

Kontrolle 1:32000

Kontrolle 1:64 000

Kontrolle 1:128 000

Kontrolle 1:256 000

Kontrolle 1:512 000

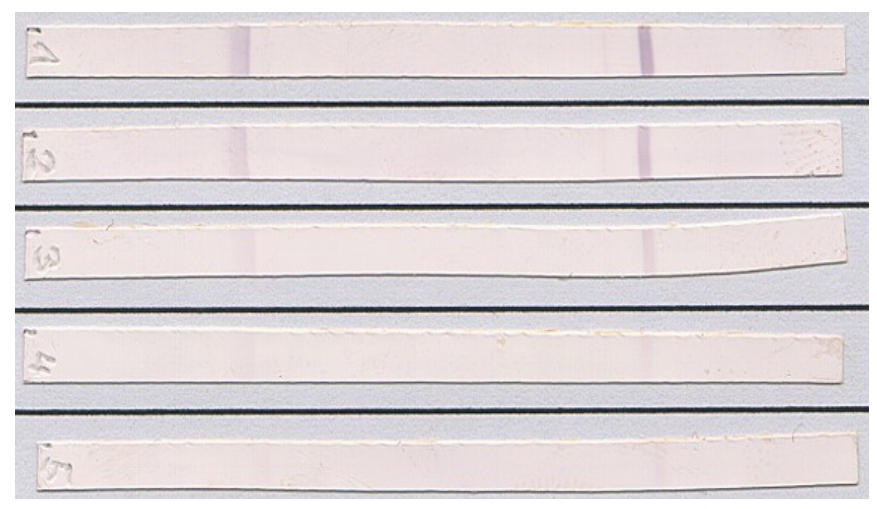

Patientenserum positiv

Patientenserum negativ

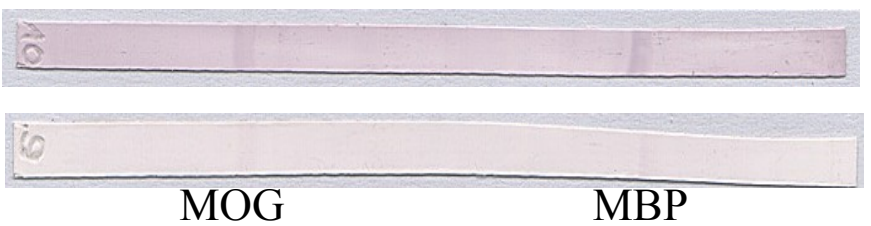

Abb.4: Beispiel nach Färbung: Absteigende Maus-Kontroll- und Patientenseren (links MOG, rechts MBP)

\subsection{Patienten}

Nach Auswertung aller Daten ergab sich eine Probandenzahl von 25 der ursprünglich 37 Patienten. Für intraindividuelle Verlaufsbeobachtungen lagen von 10 verschiedenen 
Patienten mindestens 2 bis maximal 13 Proben aus unterschiedlichen Zeitpunkten vor Diagnose der MS vor. 4 Patienten hatten zweimal Blut gespendet, 2 Patienten dreimal, ein Patient fünfmal, 2 Patienten siebenmal und von einem Patienten lagen 13 verschiedene Proben vor. 33 der behandelnden Ärzte und Kliniken konnten uns Arztbriefe aus der Zeit der Erstdiagnose zur Verfügung stellen. 4 der teilnehmenden Patienten lehnten die Auswertung ihrer klinischen Daten ab. Weitere 4 Patienen konnten für die zweite Blutabnahme nicht mehr kontaktiert werden und wurden daher ebenfalls nicht in die Auswertung miteinbezogen. Die Arztbriefe wurden im Hinblick auf den Zeitpunkt des CIS in Bezug auf die Spende der Blutprobe, die Symptomatik und den EDSS der Patienten nach CIS ausgewertet. Einen Überblick hierzu gibt Tab.3. 


\begin{tabular}{|c|c|}
\hline Gesamtanzahl Patienten & 25 \\
\hline Gesamtanzahl Proben & 61 \\
\hline Alter (Median) & 30 Jahre \\
\hline Geschlecht m/w & $5 / 20$ \\
\hline \multicolumn{2}{|l|}{ Zeit vor CIS in Monaten } \\
\hline $\begin{array}{l}\text { 1-6 Mo } \\
7-12 \mathrm{Mo} \\
13-18 \mathrm{Mo} \\
19-24 \mathrm{Mo} \\
25-30 \mathrm{Mo} \\
31-36 \mathrm{Mo} \\
37-42 \mathrm{Mo} \\
43-48 \mathrm{Mo} \\
>48 \mathrm{Mo}\end{array}$ & $\begin{array}{l}5 \text { Proben von } 4 \text { Patienten } \\
7 \text { Proben von } 6 \text { Patienten } \\
9 \text { Proben von } 9 \text { Patienten } \\
6 \text { Proben von } 5 \text { Patieten } \\
5 \text { Proben von } 4 \text { Patienten } \\
6 \text { Proben von } 6 \text { Patienten } \\
6 \text { Proben von } 5 \text { Patienten } \\
4 \text { Proben von } 3 \text { Patienten } \\
13 \text { Proben von } 4 \text { Patienten }\end{array}$ \\
\hline \multicolumn{2}{|l|}{ Erstsymptomatik } \\
\hline $\begin{array}{c}\text { - Sensorium } \\
\text { - Sehfunktion } \\
\text { - Pyramidenbahn } \\
\text { - Zerebellum } \\
\text { - Hirmstamm } \\
\text { - Cerebrum } \\
\text { Multifokale Erstsymptomatik } \\
\text { Myelitische Läsion bei CIS }\end{array}$ & $\begin{array}{l}15 \\
5 \\
5 \\
3 \\
2 \\
1 \\
4 \\
9 \\
\end{array}$ \\
\hline \multicolumn{2}{|l|}{ EDSS bei Erstsymptomatik } \\
\hline $\begin{array}{c}-0 \\
-1 \\
-1,5 \\
-2 \\
-2,5\end{array}$ & $\begin{array}{l}9 \\
8 \\
4 \\
2 \\
2\end{array}$ \\
\hline Probe von 2007 & 19 \\
\hline
\end{tabular}

Tab.3.: Charakteristika Patientenkollektiv

Die Abstände der Blutspenden zum Zeitpunkt des CIS wurden in 9 Gruppen von jeweils einem halben Jahr eingeteilt. Hatte ein Patient vor Auftreten des CIS häufiger als einmal Blut gespendet, wurden die Proben einzeln getestet und auf die verschiedenen Gruppen verteilt.

Insgesamt zeigten 15 Patienten Störungen im sensorischen System, 5 Patienten Störungen 
der Pyramidenbahn, 4 Patienten hatten Störungen der Sehfunktion. Bei 3 Patienten konnte eine Kleinhirnsymptomatik beobachtet werden, bei 3 Patienten eine Hirnstammsymptomatik, kognitive Defizite zeigte 1 Patient. Das Auftreten disseminierter Symptomatiken bei Erstmanifestation der MS wird gemeinhin als multifokal bezeichnet, dieses war bei 4 Patienten der Fall.

Nach CIS zeigten 9 Patienten einen EDSS von 0, bei weiteren 8 betrug er 1, bei 4 Patienten 1,5. Ein EDSS von 2 trat bei 2 Patienten auf, ein EDSS von 2,5 bei ebenfalls 2 Patienten. Ein höherer Behinderungsgrad konnte nach einem CIS in dieser Kohorte nicht beobachtet werden.

\subsection{Qualität der Proben}

Etwas über die Hälfe der uns von den Blutspendediensten zur Verfügung gestellten Proben stand als Plasma, die Übrigen als Serum zur Verfügung. Ein Vergleich der Antikörpervorkommen der beiden Gruppen im Western Blot zeigt jedoch ein annähernd gleiches Bild. (Abb.5)

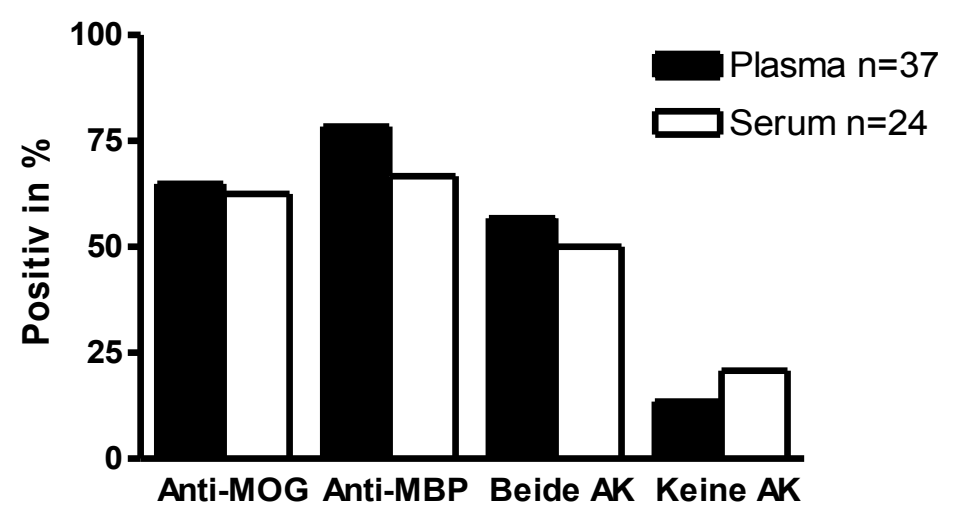

Abb.5: Antikörpervorkommen in Serumproben und Plasmaproben

Desweiteren waren zwei Drittel der verwandten Proben in aufgetautem Zustand in unserem Labor angekommen, die übrigen waren auf Trockeneis in gefrorenem Zustand versandt worden. Um die Vergleichbarkeit aller Proben sicherzustellen, wurde in einem Zusatzversuch der Vorbereitungsphase eine einzelne Probe dreimal aufgetaut und wieder eingefroren und nach jedem Tauvorgang auf die Antikörper getestet. Hierbei konnte keine 
relevante Verminderung der Farbintensität im Western Blot festgestellt werden. (Abb.6)

Serum $1 \mathrm{x}$ aufgetaut $\operatorname{IgG}$

Serum 1x aufgetaut IgM

Serum $2 x$ aufgetaut $\operatorname{IgG}$

Serum 2x aufgetaut IgM

Serum $3 x$ aufgetaut $\operatorname{IgG}$

Serum $3 x$ aufgetaut IgM

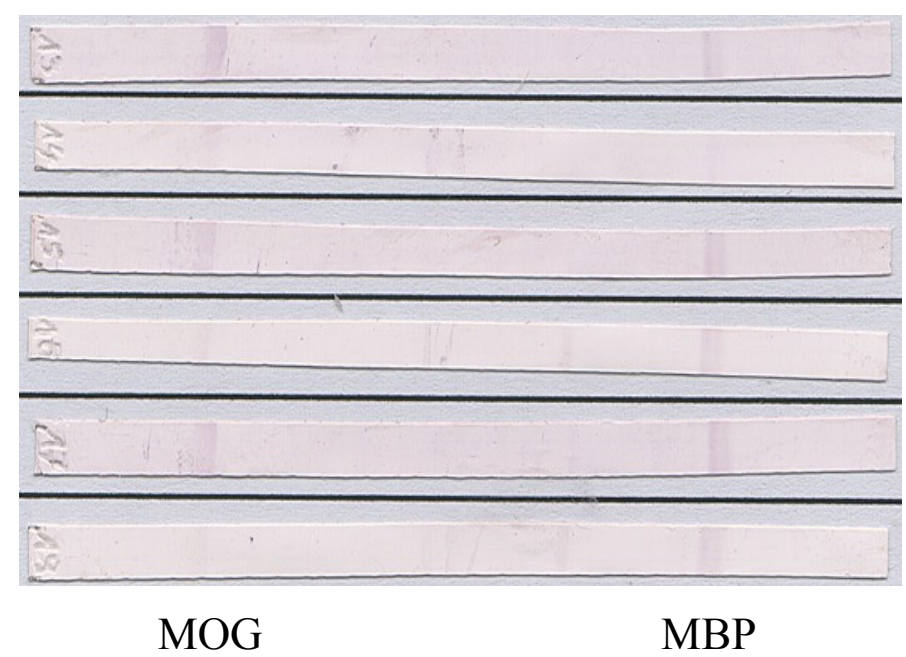

Abb.6: Versuch zur Vergleichbarkeit aufgetauter und gefrorener Serumproben (links MOG, rechts MBP)

\subsection{Vorkommen von Anti-MOG und Anti-MBP-Antikörpern im Western Blot}

\subsubsection{Patienten- und Kontrollkollektiv}

Insgesamt konnte zwar eine Tendenz zu gehäuftem Vorkommen von Antikörpern im Patientenkollektiv und im Gegensatz dazu dem Fehlen jeglicher Antikörper im Kontrollkollektiv festgestellt werden, die Zahlen waren jedoch nicht signifikant (Abb.7). Im einzelnen waren im Kontrollkollektiv 8\% positiv für Anti-MOG-IgG, 28\% positiv für Anti-MOG IgM, 32\% für Anti-MBP-IgG und 24\% für Anti-MBP-IgM. Ein Vorkommen beider Antikörper wurde bei $12 \%$ nachgewiesen, keine der getesteten Antikörper fanden sich bei $40 \%$.

Da von mehreren Patienten Proben von verschiedenen Zeitpunkten vorhanden waren, wurde die Analyse sowohl unter Einbezug nur der ältesten Probe als auch nur der jüngsten Probe durchgeführt. Hierbei fand sich kein signifikanter Unterschied.

Die Auswertung mit den ältesten Proben zeigten MOG-Antikörper bei $16 \%$ für IgG und $44 \%$ für IgM. Anti-MBP-IgG traten hier bei $64 \%$ auf, Anti-MBP-IgM bei $44 \%$. AK sowohl 
gegen MOG als auch gegen MBP hatten 36\%, keine AK dagegen nur 16\% der Proben.

Unter Einbezug der jüngsten Probe ergab sich nur ein minimaler Unterschied mit 24\% AntiMOG-IgG, 44\% Anti-MOG-IgM, 64\% Anti-MBP-IgG und 48\% Anti-MBP-IgM. Beide AK traten hier bei $44 \%$ auf, keine der getesteten AK bei 16\% der Proben. (Abb.7)
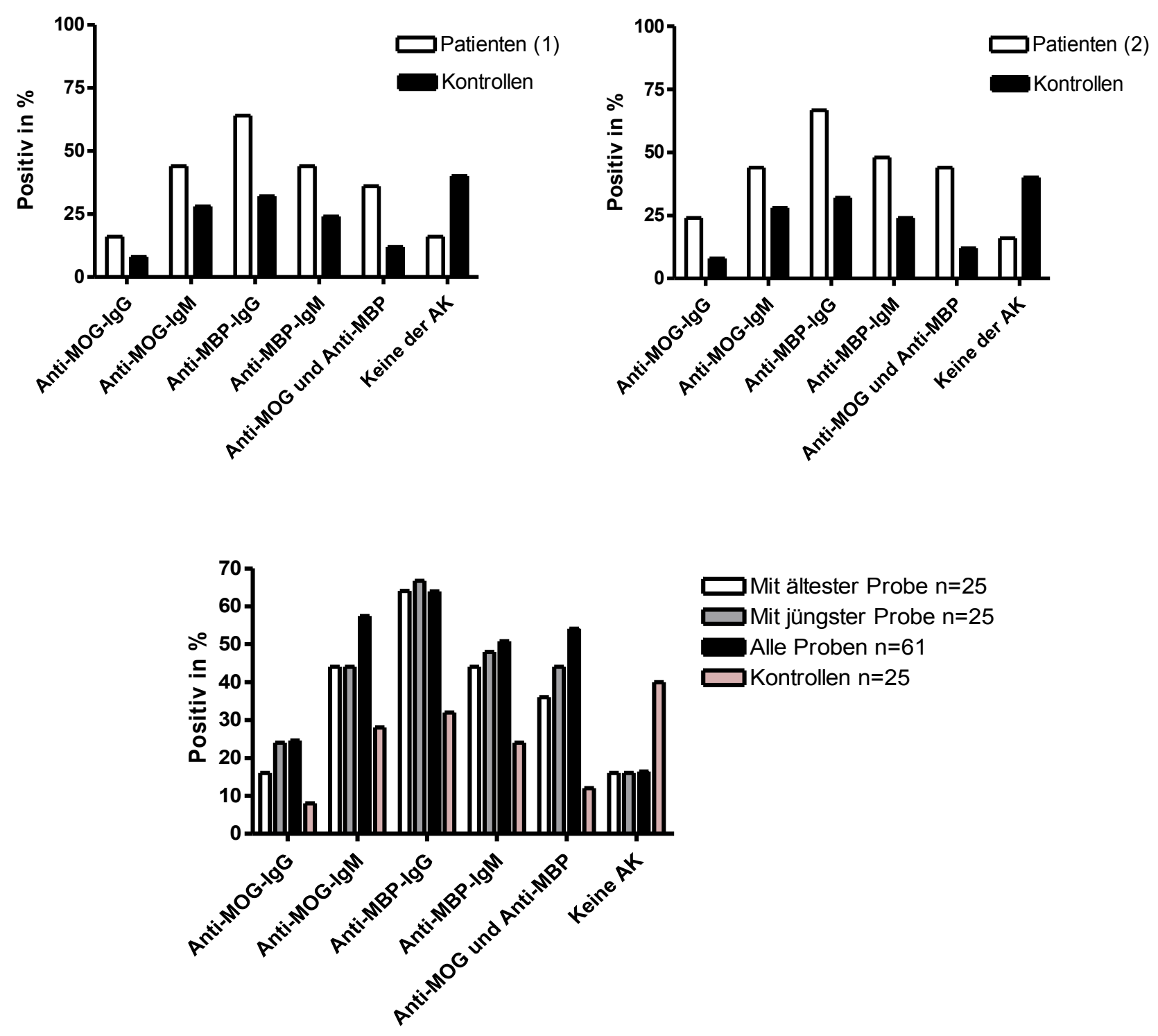

Abb.7: Anti-MOG- und Anti-MBP-AK im Patienten- und im Kontrollkollektiv. Mit den ältesten Blutspenden der Patienten (oben links) und den jüngsten (oben rechts) sowie alle Gruppen mit dem Gesamtpool im Vergleich (unten) 


\subsubsection{Inter- und intraindividueller Verlauf}

Um eine Verlaufsbeobachtung über die Zeit vor Ausbruch der Krankheit zu ermöglichen, wurden die Proben je nach dem Zeitpunkt der Blutspende in Bezug auf das CIS in Gruppen eingeteilt, die jeweils 6 Monate umfassen. Tabelle 4 zeigt die Einteilung der Zeitspannen vor CIS.

\begin{tabular}{|c|c|c|c|c|c|c|c|c|c|}
\hline & $\begin{array}{l}\text { Gruppe a } \\
n=5\end{array}$ & $\begin{array}{l}\text { Gruppe b } \\
n=7\end{array}$ & $\begin{array}{l}\text { Gruppe c } \\
\mathbf{n}=9\end{array}$ & $\begin{array}{l}\text { Gruppe d } \\
n=6\end{array}$ & $\begin{array}{l}\text { Gruppe e } \\
n=5\end{array}$ & $\begin{array}{l}\text { Gruppe f } \\
n=6\end{array}$ & $\begin{array}{l}\text { Gruppe g } \\
n=6\end{array}$ & $\begin{array}{l}\text { Gruppe } h \\
n=4\end{array}$ & $\begin{array}{l}\text { Gruppe i } \\
\mathbf{n}=13\end{array}$ \\
\hline Zeitraum & $1-6$ & $7-12$ & $13-18$ & $19-24$ & $25-30$ & $31-36$ & $37-42$ & $43 \quad-48$ & $>49$ \\
\hline $\begin{array}{l}\text { bis CIS in } \\
\text { Monaten }\end{array}$ & Monate & Monate & Monate & Monate & Monate & Monate & Monate & Monate & Monate \\
\hline
\end{tabular}

Tab.4.: Einteilung der Proben in Gruppen nach dem Zeitraum bis zum CIS

Von 19 der 25 Patienten lag eine Serumprobe von 2007, also nach Manifestation der MS, vor.

In der interindividuellen Auswertung konnte insgesamt keine Zunahme der MOG- oder MBP-AK über die Zeit beobachtet werden. Anti-MOG-IgG konnten bei den Proben der ersten fünf Gruppen (a-e) in 20\%,14\%, 11\%, $0 \%$ und $0 \%$ nachgewiesen werden, also zunächst ein Anstieg der Antikörpervorkommen über die Zeit. Dagegen zeigten die Gruppe $\mathrm{f}$ wieder $17 \%$ Positivität, die Gruppe g und h $50 \%$ und $75 \%$ und die Gruppe i $39 \%$, so dass keine Kontinuität beobachtet werden konnte.

Ähnliche Schwankungen ergab die Auswertung für Anti-MOG-IgM (Abb.8).

Für MBP-AK konnte ebenfalls kein Anstieg der Antikörpervorkommen über die Zeit abgeleitet werden.

Auch die Bestimmung der gleichzeitig vorkommenden Antikörper gegen beide Myelinbestandteile zeigte keine eindeutige Tendenz, sondern starke Schwankungen über die Zeit. 

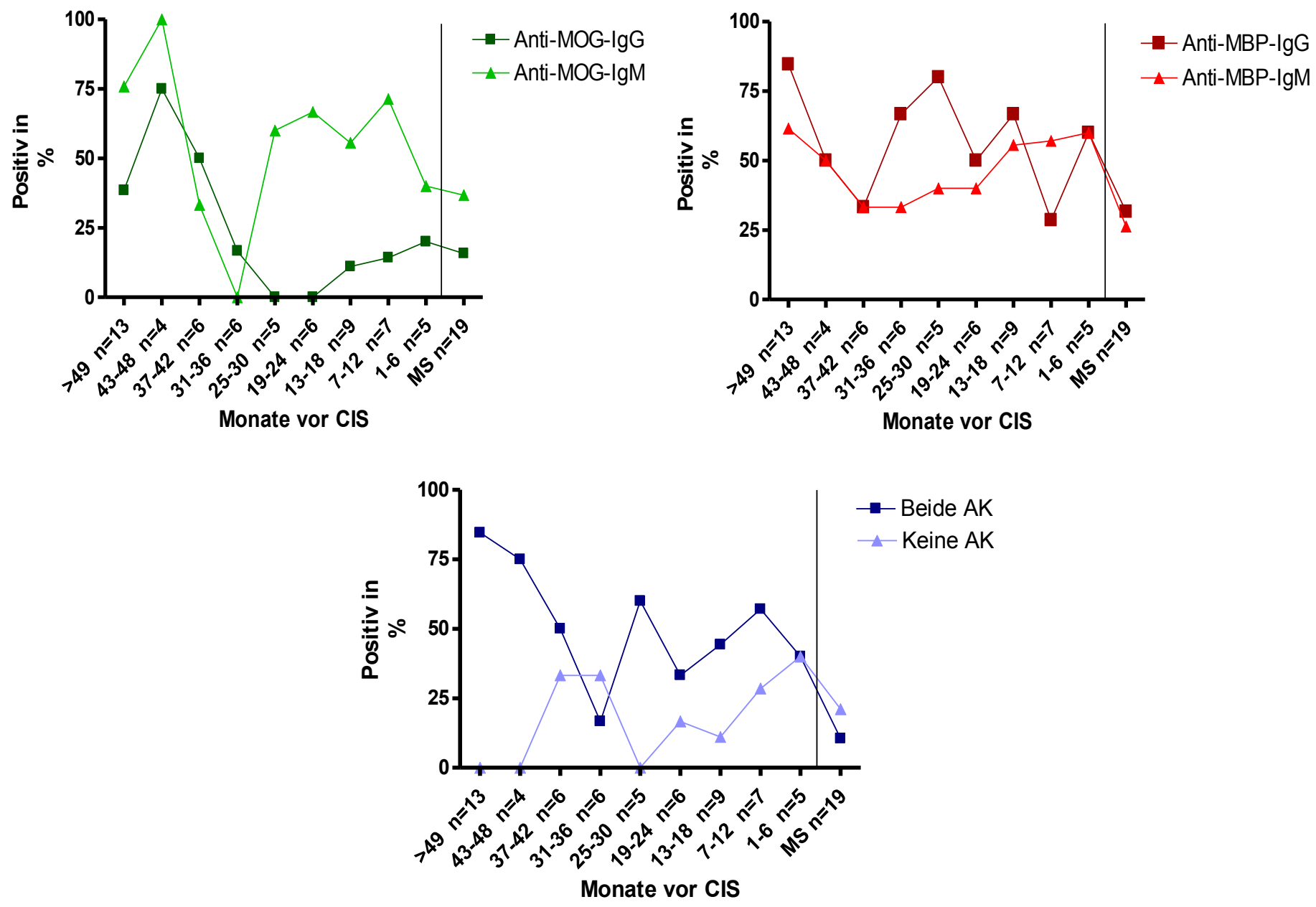

Abb.8 Anti-MOG- und Anti-MBP-AK im Verlauf links in grün: MOG; rechts in rot: MBP; unten in blau: beide/keine AK

Die Abbildung zeigt den zeitlichen Verlauf des Antikörpervorkommens von links nach rechts im Zeitraum von mehr als 4 Jahren bis zu einem Monat vor Ausbruch der Erkrankung. Ganz rechts sind die nach Diagnosestellung abgenommenen Proben dargestellt. Bei allen getesteten Antikörpern wie auch im Nachweis beider oder keiner der Antikörper wird das Fehlen einer linearen Entwicklung über die Zeit deutlich.

Die Betrachtung der einzelnen Individuen zeigt ebenfalls keine Entwicklung von MOGoder MBP-AK über die Zeit, auch ist bei den einzelnen Individuen kein zuverlässig gleichbleibend messbarer AK-Titer nachzuweisen (Tab. 5a und b).

Waren mehrere Proben eines Patienten für einen Zeitabschnitt vorhanden, wurde die jeweils jüngste Probe einbezogen. 


\begin{tabular}{|c|c|c|c|c|c|c|c|c|c|c|c|c|c|c|c|c|c|c|c|c|}
\hline MOG & \multicolumn{2}{|c|}{ Patient 1} & \multicolumn{2}{|c|}{ Patient 2} & \multicolumn{2}{|c|}{ Patient 3} & \multicolumn{2}{|c|}{ Patient 4} & \multicolumn{2}{|c|}{ Patient 5} & \multicolumn{2}{|c|}{ Patient 6} & \multicolumn{2}{|c|}{ Patient 7} & \multicolumn{2}{|c|}{ Patient 8} & \multicolumn{2}{|c|}{ Patient 9} & \multicolumn{2}{|c|}{ Patient 10} \\
\hline & $I g G$ & $\operatorname{Ig} M$ & $I g G$ & $I g M$ & $I g G$ & $I g M$ & $\operatorname{Ig} G$ & $I g M$ & $\operatorname{Ig} G$ & $I g M$ & $I g G$ & $I g M$ & $I g G$ & IgM & $I g G$ & IgM & $I g G$ & $I g M$ & $\operatorname{Ig} G$ & $I g M$ \\
\hline$>42 \mathrm{Mo}$ & & & & & + & + & - & + & - & - & & & & & & & & & & \\
\hline 43-48 Мo & & & & & + & + & & & & & & & & & & & + & + & & \\
\hline 37-42 Mo & & & & & + & + & - & + & & & & & & & - & - & + & - & - & - \\
\hline 31-36 Мo & & & - & - & & & & & & & & & & & - & - & & & + & - \\
\hline 25-30 Mo & & & & & & & - & + & - & + & & & & & & & & & & \\
\hline 19-24 Mo & - & + & - & - & & & - & + & & & & & & & & & & & & \\
\hline 13-18 Mo & - & - & & & & & - & + & - & + & - & - & - & + & & & & & & \\
\hline 7-12 Мо & - & + & & & & & - & + & - & - & + & + & - & + & & & & & & \\
\hline 1-6 Mo & & & & & & & - & + & - & - & + & + & & & & & & & & \\
\hline MS & - & + & - & - & & & - & - & - & + & + & - & - & - & - & - & - & - & + & - \\
\hline
\end{tabular}

Tab.5a: Intraindividuelle Verlaufsbeobachtung der Anti-MOG-AK

\begin{tabular}{|c|c|c|c|c|c|c|c|c|c|c|c|c|c|c|c|c|c|c|c|c|}
\hline МВP & \multicolumn{2}{|c|}{ Patient 1} & \multicolumn{2}{|c|}{ Patient 2} & \multicolumn{2}{|c|}{ Patient 3} & \multicolumn{2}{|c|}{ Patient 4} & \multicolumn{2}{|c|}{ Patient 5} & \multicolumn{2}{|c|}{ Patient 6} & \multicolumn{2}{|c|}{ Patient 7} & \multicolumn{2}{|c|}{ Patient 8} & \multicolumn{2}{|c|}{ Patient 9} & \multicolumn{2}{|c|}{ Patient 10} \\
\hline & $I g G$ & $I g M$ & $I g G$ & $I g M$ & $I g G$ & IgM & $I g G$ & $\operatorname{Ig} M$ & $\operatorname{Ig} G$ & $I g M$ & $\operatorname{Ig} G$ & $I g M$ & $\operatorname{Ig} G$ & $I g M$ & $I g G$ & $I g M$ & $I g G$ & $I g M$ & $\operatorname{Ig} G$ & $I g M$ \\
\hline$>42 \mathrm{Mo}$ & & & & & + & - & + & + & + & + & & & & & & & & & & \\
\hline 43-48 Мo & & & & & + & + & & & & & & & & & & & - & - & & \\
\hline 37-42 Мo & & & & & + & + & + & + & & & & & & & - & - & - & - & - & - \\
\hline 31-36 Мo & & & - & - & & & & & & & & & & & - & - & & & + & - \\
\hline 25-30 Mo & & & & & & & + & + & + & - & & & & & & & & & & \\
\hline 19-24 Mo & - & - & - & - & & & + & + & & & & & & & & & & & & \\
\hline 13-18 Мo & + & - & & & & & + & + & + & + & + & - & + & + & & & & & & \\
\hline 7-12 Мо & - & - & & & & & + & + & - & - & - & + & - & + & & & & & & \\
\hline 1-6 Mo & & & & & & & + & + & - & - & + & + & & & & & & & & \\
\hline MS & - & - & - & - & & & + & + & - & - & - & - & + & - & - & - & - & - & & - \\
\hline
\end{tabular}

Tab.5b: Intraindividuelle Verlaufsbeobachtung der Anti-MBP-AK

\subsubsection{Korrelation mit der Symptomatik des CIS}

Das am häufigsten vorkommende Erstsymptom in diesem Patientenkollektiv war eine Störung der Sensibilität im Sinne von Dys- oder Hypästhesien. Auch die in der Literatur als Kardinalssymptom einer beginnenden MS beschriebene Sehstörung, meist in Form einer Optikusneuritis, sowie die Affektion der motorischen Bahnen stellten hier eine häufige Klinik des CIS dar. Seltener fanden sich Störungen der Kleinhirn- und Hirnstammfunktionen. Nur ein Patient zeigte eine zerebrale Symptomatik mit kognitiven Einbußen. Disseminierte Läsionen mit konsekutiven Störungen verschiedener Funktionssysteme (multifokal) kamen nur bei einem Fünftel der Patienten vor, eine 
Schädigung der Bahnen im Rückenmark (myelitischer Schaden) konnte bei mehr als einem Drittel ausgemacht werden.

Ein Zusammenhang bestimmter Antikörper mit der initial auftretenden Symptomatik wurde nicht beobachtet.

In der Gruppe mit den sensiblen Ausfällen wiesen 20\% Anti-MOG-IgG auf, 53\% AntiMOG-IgM, 60\% Anti-MBP-IgG und 40\% Anti-MBP-IgM. Beide Arten von AK zeigten sich bei $47 \%$, bei $20 \%$ konnten keine AK gefunden werden.

Eine Pyramidenbahnläsion ging bei keinem der Patienten mit Anti-MOG-IgG einher, bei 40\% mit Anti-MOG-IgM. Alle Patienten zeigten aber Anti-MBP-IgG und 80\% Anti-MBPIgM. Bei 40\% konnten beide AK und bei keiner Probe gar keine AK nachgewiesen werden. Bei den Patienten mit Sehstörungen konnten bei 40\% Anti-MOG-IgG gefunden werden, bei keinem Anti-MOG-IgM, bei 40\% Anti-MBP-IgG und bei 20\% Anti-MBP-IgM. Beide AK zeigten in dieser Gruppe 20\% der Proben, $40 \%$ gar keine AK.

Mit Kleinhirnsymptomatik einhergehend waren bei einem Drittel der Patienten Anti-MOGIgG, bei zwei Dritteln Anti-MOG-IgM, insgesamt keine MBP-Antikörper. Auch bei jeweils einem Drittel der Proben wurden beide oder keine AK nachgewiesen. (Diese Gruppe weist allerdings, ebenso wie die beiden folgenden mit Hirnstamm- oder zerebralen Läsionen, eine Patientenzahl kleiner 4 auf, wird der Vollständigkeit halber aber dennoch aufgeführt.)

Bei keinem Patienten mit Hirnstammsymptomatik wurden Anti-MOG-IgG, bei jeweils einem Anti-MOG-IgM und Anti-MBP-IgG nachgewiesen. Beide wiesen Anti-MBP-IgM, je ein Patient beide AK und keiner gar keine AK auf.

Der einzelne Patient mit den kognitiven Störungen wies lediglich Anti-MBP-IgG auf. In der Gruppe mit multifokalen Störungen wurden bei keinem Anti-MOG-IgG gefunden und bei jeweils einem Viertel der Proben Anti-MOG-IgM, Anti-MBP-IgG und Anti-MBP-IgM. Beide AK fanden sich hier bei keinem und keine AK bei der Hälfte der Patienten.

Bei der Betrachtung der Gruppe mit myelitischen Schädigungen zeigte sich bei 11\% AntiMOG-IgG, bei 33\% Anti-MOG-IgM, bei 78\% Anti-MBP-IgG und bei 44\% Anti-MBP-IgM. Beide AK zeigten sich bei $33 \%$ und keine der AK bei 11\%. (Abb.9) 


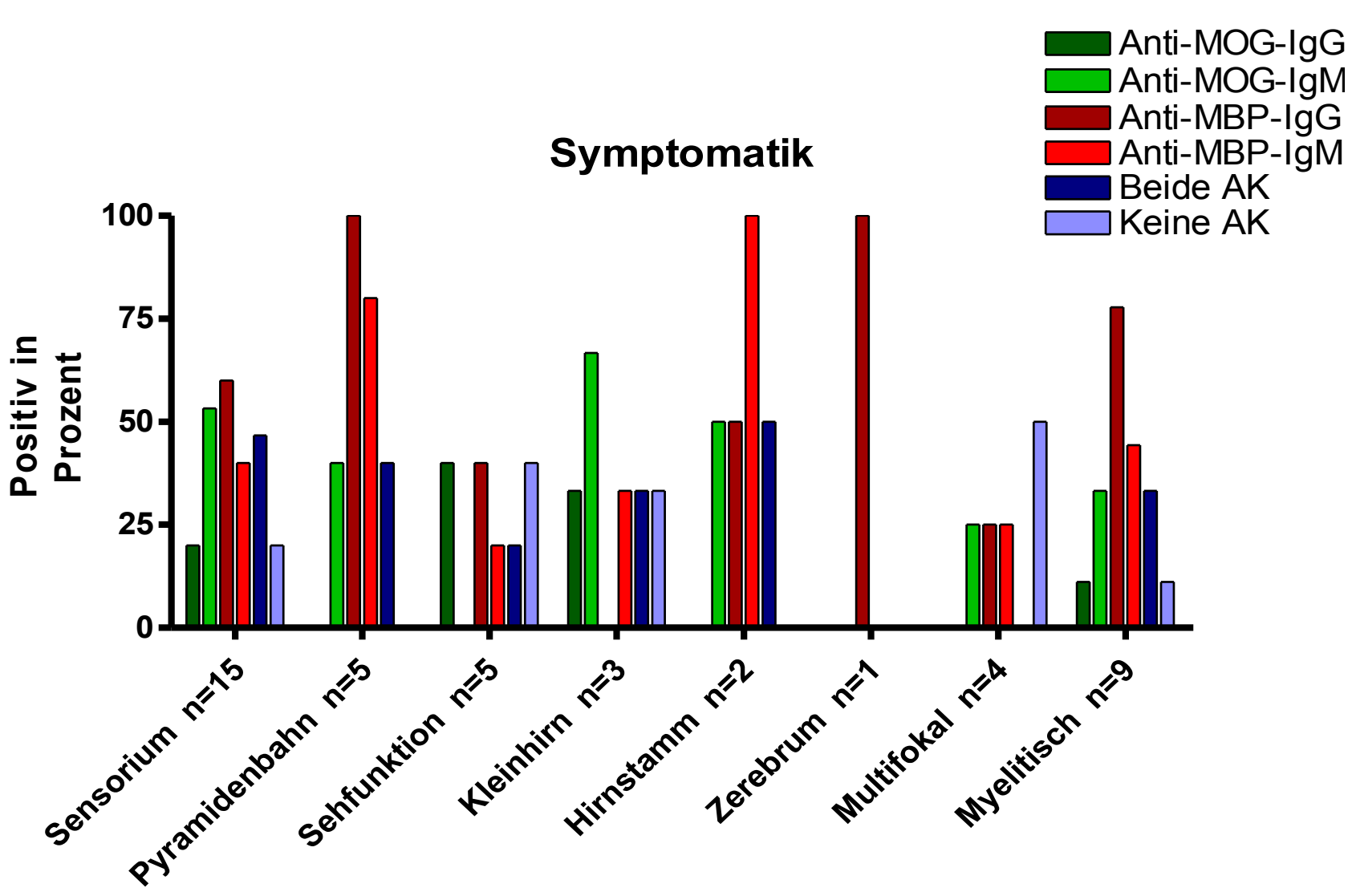

Abb.9: Verteilung der Antikörper auf die nach Erstsymptomatik aufgeteilten Gruppen

( $\mathrm{Zu}$ besseren Vergleichbarkeit Aufführung des einzelnen Patienten mit zerebraler Symptomatik als Gruppe mit der Fallzahl n=1)

\subsubsection{Korrelation mit dem EDSS bei CIS}

Bei Erstmanifestation einer MS war im vorliegenden Kollektiv am häufigsten ein EDSS von 0 und 1. Eine schwerere Symptomatik zeigten weniger Patienten, die höchste hier vorkommende EDSS mit der Einstufung auf 2,5 erhielten 2 Patienten, von denen beide myelitische Läsionen aufwiesen.

Auch bei dieser Auswertung wurden die Angaben in Prozent der Gruppe umgerechnet und die jeweils jünsten Proben verwandt.

Beim EDSS von 0 zeigten sich 33\% positiv für Anti-MOG-IgG, 44\% für Anti-MOG IgM, 56\% für Anti-MBP-IgG und 22\% für Anti-MBP-IgM. Beide Antikörper kamen bei 33\% und keine Antikörper bei 22\% vor. 
In der Gruppe mit einem EDSS von 1 traten bei 14\% Anti-MOG-IgG, bei 63\% Anti-MOGIgM, bei je 75\% Anti-MBP-IgG und Anti-MBP-IgM auf. Beide Antikörper fanden sich hier bei $63 \%$, das Fehlen beider AK kam nicht vor.

Bei den Patienten mit der Einstufung auf den EDSS von 1,5 traten sowohl Anti-MOG-IgG als auch Anti-MOG-IgM nicht auf. Die Hälfte der Proben waren positiv für Anti-MBP-IgG und ein Viertel für Anti-MBP-IgM, somit waren beide Antikörper nicht und keine Antikörper in der Hälfte der Proben vorhanden.

Von den Proben der beiden Patienten mit EDSS 2 war je eine, also 50\%, positiv für AntiMOG-IgG, Anti-MBP-IgG und Anti-MBP-IgM, dabei waren beide positiv für Anti-MOGIgG. Es waren in einer Probe beide und in keiner Probe kein Antikörper zu finden.

Ebenso zeigten sich bei den beiden Patienten mit EDSS 2,5 bei je einer Probe beide oder keine Antikörper. Beide wiesen hier Anti-MBP-IgG und -IgM auf, einer Anti-MOG-IgM und keine der Proben Anti-MOG-IgG. (Abb.10)

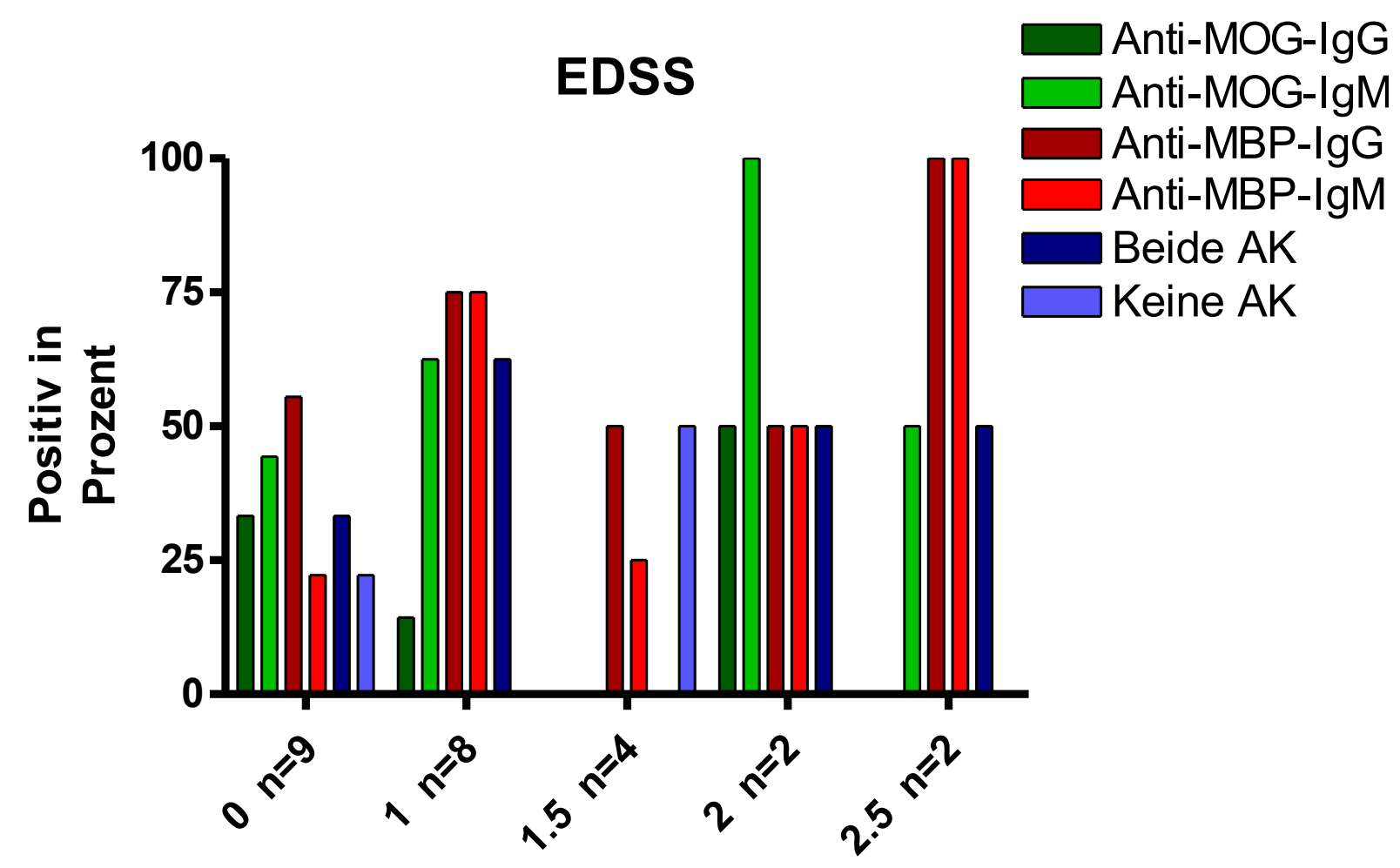

Abb.10: Verteilung der Antikörper auf die nach EDSS aufgeteilten Gruppen 


\section{Diskussion}

\subsection{Anti-MOG- und Anti-MBP-Antikörper als prädiktive Marker}

In der vorliegenden Arbeit konnte im Vergleich zu der in Geschlecht und Alter angepassten Kontrollgruppe gesunder Blutspender weder für Anti-MOG-IgG und Anti-MOG-IgM, noch für Anti-MBP-IgG und Anti-MBP-IgM ein signifikant höheres Vorkommen bei MSPatienten gefunden werden. Der Nachweis von Antikörpern gegen sowohl MOG als auch MBP war zwar in der Patientengruppe mit über 30\% höher als in der Kontrollgruppe mit 13\%, jedoch auch dies ohne statistische Signifikanz. Trotz erkennbarer Tendenzen ebenfalls nicht signifikant war das völlige Fehlen der getesteten Antikörper von $42 \%$ in der Kontrollgruppe gegen 13\% bei den Patienten.

In der anfangs bereits erwähnten Arbeit von Berger et al. (2003) wurde ein erhöhtes Risiko zur Entwicklung einer MS nach CIS für antikörperpositive Patienten bescheinigt. Dabei wurden Patienten nach CIS sowie nach dem zweiten klinischen Schub auf MOG- und MBPAntikörper untersucht. Trotz der Nutzung des gleichen Western-Blot-Protokolls sowie der selben Kontroll-Antikörper konnte der postulierte prädiktive Nutzen für unsere Kohorte in diesem noch früheren Stadium nicht nachvollzogen werden. Es muss jedoch diesbezüglich auf die Unterschiede in Fragestellung und Patientenkollektiv hingewiesen werden. Schließlich wurden bei Berger et al. (2003) die Patienten erst nach der klinischen Erstsymptomatik untersucht. Des weiteren wurden Patienten ohne auffälliges MRT sowie auch die Patienten ohne pathologische Liquorbefunde aus deren Studie ausgeschlossen. In unserer Studie waren als Vorraussetzung lediglich eine ärztlich diagnostizierte MS und die zeitlich davor abgegebene Blutspende gefordert. Man könnte hier von einer möglichen Vorselektion ausgehen. $\mathrm{Zu}$ erwähnen ist hier sicherlich auch die visuelle Auswertung des Western Blots, welche trotz geblindeter und wiederholter Auswertung immer untersucherabhängig bleibt.

Ähnlich konträr waren die Ergebnisse beider Studien zur Korrelation des Antikörperstatus mit Symptomatik oder Schwere der Erkrankung.

Eine gesunde Kontroll-Kohorte lag bei Berger et al. (2003) nicht vor. Diese zeigte bei uns eine Häufigkeit beider Antikörper von immerhin 13\%. IgM- Antikörper alleine gegen MOG 
wiesen wir bei $28 \%$ und gegen MBP bei $24 \%$ nach. Positiv für IgG gegen MBP waren sogar $32 \%$ der Kontrollen. Diese relativ große Häufigkeit von Anti-Myelin-AK bei Gesunden wurde auch schon zuvor und auch mit variabler Methodik (Western Blot, ELISA, radiobinding assay) von anderen Arbeitsgruppen nachgewiesen und schließt einen rein diagnostischen Wert der Antikörper bei fehlender Spezifität aus (Rauer et al. 2006, Gaertner et al. 2004). Auch in der Folgestudie zur vorliegenden Arbeit, in welcher die Antikörper mittels Durchflusszytometrie detektiert wurden, wurden in der Kontrollkohorte hohe Titer gefunden (Chan et al. 2010).

Ebenfalls eine Bestätigung der hier vorliegenden Ergebnisse bezüglich der prädiktiven Bedeutung von Anti-MOG- und Anti-MBP-AK mit etwa gleich hohen Antikörpertitern gesunder Spender und MS-Patienten erbrachten Lampasona et al. (2004) mittels radiobinding assay, einer Methode zur quantitativen Detektion von Antikörpern, bei der die Antigene wie beim Western Blot in denaturierter Form vorliegen.

Eine 2006 veröffentlichte Studie von Lalive et al. (2006) postulierte erneut, entgegen der vorliegenden Arbeit, die These der Spezifität von Anti-MOG- und Anti-MBP-AK für MSPatienten. Als Methodik wurden dort ELISA und FACS gegenübergestellt, wobei die erwähnte hohe Spezifität lediglich mittels FACS gefunden wurde, mit welchem die Antikörper gegen das membrangebundene, nativ gefaltete Antigen detektiert werden.

$\mathrm{Zu}$ ähnlichen Ergebnissen kamen Zhou et al. (2006) in einem Vergleich von MS-Patienten mit Patienten anderer entzündlicher ZNS-Erkrankungen und gesunden Spendern. Als Detektionsmethode wurde dort ebenfalls die Durchflusszytometrie gewählt. Dem gegenüber stehen allerdings die Ergebnisse der Anschlussstudie von Chan et al. (2010), in welcher sich bei gleicher Methodik gegenteilige Ergebnisse zeigten. Die dortigen Tendenzen entsprachen bei gleichem Patientenkollektiv den hier beschriebenen Ergebnissen nach Western Blot.

\subsection{Antikörper in Verlauf und Klinik}

Ein erhöhter Spiegel der getesteten Antikörper deutet in der hier vorliegenden Arbeit nicht auf baldiges Auftreten klinischer Symptome hin, auch ein Anstieg bis zur Manifestation der Erkrankung konnte nicht gezeigt werden. Ebenso ist ein Hinweis auf eine Korrelation zur 
Krankheitsaktivität, wie in der Studie von Gaertner et al. (2004) vermutet, in diesem Kollektiv nicht zu finden. Allerdings wurden von Gaertner et al. keine Seren vor Ausbruch der Erkrankung, sondern ausschließlich MS- und CIS-Patienten in verschiedenen Krankheitsstadien mittels ELISA untersucht.

Ein Wechsel der Häufung von IgM-AK in frühen Krankheitsstadien zu IgG bei manifester Erkrankung konnte ebenfalls nicht beobachtet werden. Auch konnte keine Korrelation zur Symptomatik oder der Schwere des CIS herausgearbeitet werden. Erneut steht dem gegenüber eine andere Studie von Menge et al. (2011), in welcher sich für Anti-MOG eine Korrelation mit der Krankheitsaktivität fand. Auch dort wurde mittels ELISA gearbeitet. Insgesamt sind die differenten Ergebnisse wohl auf die verschiedenen Detektionsmethoden zurückzuführen.

\subsection{Wertigkeit des Western Blot in dieser Fragestellung}

Kritisch betrachtet werden muss sicherlich die hier angewandte Methode des Western Blots für die vorliegende Fragestellung.

Bei der Auswertung eines Western Blots ist eine gewisse Ungenauigkeit der Ergebnisse durch die unterschiedlich behandelten Proben sicherlich nicht auszuschließen, da die Serumproben von insgesamt 15 verschiedenen Blutspendeinstituten zur Verfügung gestellt worden waren. Letztendlich ist auch die Auswertung eines Western Blots, wie oben bereits erwähnt, immer untersucherabhängig. Diese Problematik versuchten wir durch eine unabhängige zweifache Bewertung und durch einen geblindeten und in dieser Auswertung erfahrenen Untersucher zu minimieren.

Insgesamt scheinen die unter denaturierenden Bedingungen durchgeführten Methoden, zu denen auch der Western Blot gehört, die realistische Situation in vivo möglicherweise nur unzureichend widerzuspiegeln. Sie zeigen schließlich lediglich die Antikörper auf, welche gegen lineare Proteine, die nur zu geringem Anteil an der Myelinoberfläche positioniert sind, gerichtet sind. Die tatsächliche Pathogenität dieser AK ist noch immer fraglich. Ihr Potential, demyelinisierende Erkrankungen auszulösen, wurde in der Vergangenheit durch zahlreiche Studien sowohl bewiesen wie auch widerlegt (Lyons et al. 2002, Brehm et al. 1999). 
Desweiteren kann bei der Detektion von Antikörpern gegen MOG mittels Western Blot im Allgemeinen nicht unterschieden werden, gegen welche Aminosäuresequenzen die AK gerichtet sind. Dass die gegen unterschiedliche Sequenzen des MOG gerichteten AK sowohl unterschiedliche Pathogenität wie auch Häufigkeitsverteilungen besitzen, wurde bereits mehrfach herausgearbeitet (Khalil et al. 2006, Menge et al. 2011). Wahrscheinlich können aber vor allem die AK, die gegen ein in seiner Tertiärstruktur natürlich gefaltetes Protein gerichtet sind, tatsächlich eine Demyelinisierung verursachen. Möglicherweise besitzen die AK gegen einzelne Peptide des MOG lediglich einen verstärkenden Effekt bei schon initialisierter Entzündungsreaktion (Khalil et al. 2006, Marta et al. 2005, von Büdingen et al. 2002).

\subsection{Beurteilung und Ausblick}

Obwohl Anti-MOG- und Anti-MBP-AK in der hier vorliegenden Studie kein diagnostischer oder prädiktiver Wert zugeschrieben werden kann, ist eine Relevanz dieser Antikörper für die Pathogenese der MS sehr wahrscheinlich.

Ein weiterer Ansatz zu Klärung der Rolle der Serum-AK in der MS ist in einer Studie von O 'Connor et al. 2005 gegeben worden, in der ein Vergleich von Serum- und Liquor-AK mit aus ZNS-Läsionsgewebe isolierten AK angestellt wurde. Dieser ergab eine deutlich höhere Affinität der Gewebe-AK zu MOG, woraus sich eine möglicherweise geringere Pathogenität der Serum-AK ableiten läßt.

Die Heterogenität des Auftretens von Anti-Myelin-AK bei MS-Patienten könnte durchaus auch durch verschiedene der Erkrankung zugrundeliegende Pathomechanismen zu erklären sein. Wie einleitend beschrieben, lassen sich die zerebralen Läsionen von MS-Patienten in 4 Kategorien einteilen. Da hieraus auch auf unterschiedliche Pathomechanismen rückgeschlossen werden kann, könnte darin eine physiologische Heterogenität in der Häufigkeit von Anti-Myelin-AK bei MS-Patienten gesehen werden. Es gibt bereits Studien, in denen Zusammenhänge der Pathogenesegruppe mit der Wirksamkeit bestimmter Behandlungen herausgestellt wurden. So profitieren die Patienten der Gruppe II, welche in den Läsionen vor allem eine Aktivität von Antikörpern und aktivierten Komplementfaktoren 
aufweisen, mehr als andere Patienten von einer Akutbehandlung mit Plasmapherese. (Linker et al. 2007, Lucchinetti et al. 2000, Lassmann et al. 2001) Weitere Korrelationen sind vorstellbar, wonach eine serologische Untersuchung, möglicherweise mit Serum- oder Liquorantikörpern eine schnelle und günstige Möglichkeit der Unterscheidung der 4 Gruppen darstellen würde. Diesbezüglich sind allerdings die in der vorliegenden Arbeit betrachteten Antikörper Anti-MOG und Anti-MBP eher nicht relevant.

Auch eine Relevanz zumindest für Anti-MOG-AK ist in der Untergruppe der pädiatrischen MS- wie auch ADEM-Patienten postuliert worden (McLaughlin et al. 2009, Brilot et al. 2009). Wie in den bereits erwähnten Arbeiten wurden dabei sowohl die Durchflusszytometrie wie auch der radiobinding assay benutzt. Auch bei Erwachsenen konnte in anderem Zusammenhang ein prospektiver Wert von Anti-MOG-AK belegt werden, nämlich für die in der Krankheitsentstehung der MS ähnlichen Neuromyelitis optica (Mader et al. 2011, Kitley et al. 2012). Dies deutet erneut auf eine Abhängigkeit der Relevanz der Antikörper von der spezifischen Pathogenese hin.

Eine prospektive Studie von Wang et al. 2008, in der mehr als 7 Millionen US-Soldaten auf Anti-MOG-AK untersucht wurden, zeigte ein erhöhtes Risio für die Entwicklung einer MS bei Personen mit Anti-MOG-IgG. Allerdings wurde bei den betreffenden Personen auch eine Korrelation mit dem Ebstein-Barr-Virus beobachtet, was auf eine Kreuzreaktivität hindeutet und den prädiktiven Wert des AK relativiert. Jedoch könnte die Zusammenschau von Anti-Myelin-, antiviralen (wie dem Anti-EBV-AK) und weiteren für sich genommen nicht MS-spezifischen Antikörpern künftig eine Rolle im Hinblick auf die Prognose der Entwicklung einer MS nach CIS wie auch im Hinblick auf den Verlauf der Erkrankung zukommen.

Wichtig erscheint in der Zukunft nicht zuletzt die Beobachtung intraindividueller Antikörpervorkommen in verschiedenen Krankheitsstadien, um ggf. Rückschlüsse auf die Krankheitsaktivität ziehen zu können.

Ebenfalls in prospektiven Studien könnte eine mögliche intraindividuelle Änderung des Antikörpervorkommens mit oder ohne immunmodulatorische Therapie zum Beispiel als späterer Marker für den Therapieerfolg ein interessantes Thema darstellen. 
Einen weiteren Fortschritt bezüglich der Aufklärung der Pathogenese der MS und damit möglicherweise auch neue Behandlungsmethoden erhofft man sich aktuell mit der Proteomik. Dabei wird das Proteom und damit die Zusammensetzung und die Proteinexpression einer Zelle detektiert, wobei im Vergleich von MS-Patienten mit Kontrollgruppen Rückschlüsse auf die Pathogenese der Erkrankung gezogen werden sollen (De Masi et al. 2013, Ayoglu et al. 2013). Diese Methodik wurde bereits erfolgreich bei Patienten mit rheumatoider Arthritis angewandt (Dotzlaw et al. 2004, Schulz et al. 2007).

\section{Zusammenfassung}

Die Erkrankung MS ist die wichtigste nicht traumatische Ursache von Behinderungen und die häufigste entzündliche ZNS-Erkrankung. Durch die Einführung der Mc-DonaldKriterien kann die MS im Vergleich zu früher relativ schnell und sicher in der Zusammenschau klinischer und bildmorphologischer Befunde diagnostiziert werden.

Die Pathogenese der Erkrankung ist jedoch weiterhin noch nicht völlig geklärt, ebenso unbewiesen ist die Rolle von Antikörpern gegen Myelinstrukturen in der Krankheitsentstehung und daraus folgend in der Diagnostik und Prognosestellung der MS. In den letzten Jahren stellte sich in der Forschung ein unumstritten positiver Effekt möglichst frühzeitigen Therapiebeginns heraus. Umso wichtiger wird eine möglichst frühzeitige Diagnosestellung und hierfür das Auffinden sicherer diagnostischer Parameter in der frühen Krankheitsphase.

In der vorliegenden Studie wurde retrospektiv das Vorkommen von Anti-MOG- und AntiMBP-Antikörpern in den Blutproben noch gesunder Blutspender untersucht, welche in den Folgejahren an MS erkrankten. Hierfür wurden von einigen Blutspendediensten konservierte Rückstellproben der Studienteilnehmer bereitgestellt. Die Plasma- und Serumproben wurden mittels Western Blot auf das Vorliegen der genannten Antikörper getestet und einem gesunden Kontrollkollektiv gegenübergestellt. Zur Verlaufskontrolle wurden auch aktuelle Proben der Patienten ausgewertet.

Hier konnte kein höheres AK-Vorkommen in den Proben der künftigen Patienten festgestellt 
werden. Es ergab sich keine Korrelation der AK mit der Art und Schwere des CIS, auch eine Entwicklung im zeitlichen Verlauf konnte nicht herausgearbeitet werden.

Weitere Studien bleiben abzuwarten. Im Hinblick auf die günstige Auswirkung einer frühen immunmodulatorischen Therapie wäre die Herausarbeitung eines einfachen und sicheren prognostischen Markers wie eines Antikörpers sehr wünschenswert. 


\section{Literaturverzeichnis}

1. Alonso A, Hernán MA (2008): Temporal trends in the incidence of multiple sclerosis: a systematic review, Neurology $\underline{71}(2): 129-35$

2. Amiguet P, Gardinier MV, Zanetta JP, Matthieu JM (1992): Purification and partial structural and functional characterization of mouse myelin/oligodendrocyte glycoprotein, $\mathrm{J}$ Neurochem. 58(5):1676-82

3. Ayoglu B, Häggmark A, Khademi M, Olsson T, Uhlén M, Schwenk JM, Nilsson P (2013): Autoantibody profiling in multiple sclerosis using arrays of human protein fragments, Mol Cell Proteomics. Sep; 12(9):2657-72

4. Belogurov AA Jr, Kurkova IN, Friboulet A, Thomas D, Misikov VK, Zakharova MY, Suchkov SV, Kotov SV, Alehin A1, Avalle B, Souslova EA, Morse HC $3^{\text {rd }}$, Gabibov AG, Ponomarenko NA (2008): Recognition and degradation of myelin basic protein peptides by serum autoantibodies: novel biomarker for multiple sclerosis, J Immunol. 180(2): 125867

5. Berger T, Rubner P, Schautzer F, Egg R, Ulmer H, Mayringer I, Dilitz E, Deisenhammer F, Reindl M (2003): Antimyelin antibodies as a predictor of clinically definite multiple sclerosis after a first demyelinating event, N Engl J Med. $\underline{349}(2): 139-45$

6. Bernardinelli L, Murgia SB, Bitti PP, Foco L, Ferrai R, Musu L, Prokopenko I, Pastorino R, Saddi V, Ticca A, Piras ML, Cox DR, Berzuini C (2007): Association between the ACCN1 gene and multiple sclerosis in Central East Sardinia, PloS One. 2(5): e480

7. Brehm U, Piddlesden SJ, Gardinier MV, Linington C (1999): Epitope specificity of demyelinating monoclonal autoantibodies directed against the human myelin oligodendrocyte glycoprotein (MOG), J Neuroimmunol. Jun 1;97(1-2):9-15.

8. Brilot F, Dale RC, Selter RC, Grummel V, Kalluri SR, Aslam M, Busch V, Zhou D, Cepok S, Hemmer B (2009): Antibodies to native myelin oligodendrocyte glycoprotein in children with inflammatory demyelinating central nervous system disease, Ann Neurol. Dec; 66(6):833-42. doi: 10.1002/ana.21916

9. Chan A, Decard BF, Franke C, Grummel V, Zhou D, Schottstedt V, Toyka KV, Hemmer B, Gold R (2010): Serum antibodies to conformational and linear epitopes of myelin oligodendrocyte glycoprotein are not elevated in the preclinical phase of multiple sclerosis, Mult Scler. 16 (10):1189-92

10. Charcot JM 1868: Histologie de la sclérose en plaques (leçon recueillie par Bourneville), Gaz Hop Civ Mil 41(140):554-555; 411(141):557-558; 1(145):566 
11. Clements CS, Reid HH, Beddoe T, Tynan FE, Perugini MA, Johns TG, Bernard CC, Rossjohn J (2003): The crystal structure of myelin oligodendrocyte glycoprotein, a key autoantigen in multiple sclerosis, Proc Natl Acad Sci U S A. 100(19):11059-64

12. Comi G (2003): From inflammation to degeneration: the lessons of clinical trials, Neurol Sci. 24 Suppl 5:S295-7

13. Comi G, Martinelli V, Rodegher M, Moiola L, Bajenaru O, Carra A, Elovaara I, Fazekas F, Hartung HP, Hillert J, King J, Komoly S, Lubetzki C, Montalban X, Myhr KM, Ravnborg M, Rieckmann P, Wynn D, Young C, Filippi M; PreCISe study group (2009): Effect of glatiramer acetate on conversion to clinically definite multiple sclerosis in patients with clinically isolated syndrome (PreCISe study): a randomized, double-blind, placebocontrolled trial, Lancet $\underline{374}$ :1503-1511

14. Compston A (1998): Future options for therapies to limit damage and enhance recovery, Semin Neurol. 18(3): 405-14.

15. Coyle PK (2008): Early treatment of multiple sclerosis to prevent neurological damage, Neurology $\underline{71}$ (24 Suppl 3): S3-7

16. della Gaspera B, Pham-Dinh D, Roussel G, Nussbaum JL, Dautigny A (1998): Membrane topology of the myelin/oligodendrocyte glycoprotein, Eur J Biochem. 258(2):478-84

17. De Masi R, Pasca S, Scarpello R, Idolo A, De Donno A (2013): The clinical potential of blood-proteomics in multiple sclerosis, BMC Neurol. May 21; 13 :45. doi: 10.1186/14712377-13-45

18. Dotzlaw H, Schulz M, Eggert M, Neeck G (2004): A pattern of protein expression in peripheral blood mononuclear cells distinguishes rheumatoid arthritis patients from healthy individuals, Biochim Biophys Acta.;13:121-129

19. Filippi M, Rovaris M, Inglese M, Barkhof F, De Stefano N, Smith S, Comi G (2004): Interferon beta-1a for brain tissue loss in patients at presentation with syndromes suggestive of multiple sclerosis: a randomised, double-blind, placebo-controlled trial, Lancet $\underline{364}(9444): 1489-96$

20. Gaertner S, de Graaf KL, Greve B, Weissert R (2004): Antibodies against glycosylated native MOG are elevated in patients with multiple sclerosis, Neurology $\underline{63}$ (12):2381-3

21. Genain CP, Cannella B, Hauser SL, Raine CS (1999): Identification of autoantibodies associated with myelin damage in multiple sclerosis, Nat Med. $\underline{5}(2): 170-5$

22. Gold R, Linington C (2002): Devic's disease: bridging the gap between laboratory and clinic, Brain. 125(Pt 7):1425-7 
23. Gold R, Rieckmann P (2004): Pathogenese und Therapie der Multiplen Sklerose, UNI-MED Verlag AG, Bremen, $\underline{3}$. Auflage

24. Greeve I, Sellner J, Lauterburg T, Walker U, Rösler KM, Mattle HP; Swiss Cohort (2007): Anti-myelin antibodies in clinically isolated syndrome indicate the risk of multiple sclerosis in a Swiss cohort, Acta Neurol Scand. 16(4):207-10

25. Hafler DA, Slavik JM, Anderson DE, O'Connor KC, De Jager P, Baecher-Allan C (2005): Multiple sclerosis, Immunol Rev. 204:208-31

26. Hafler DA, Compston A, Sawcer S, Lander ES, Daly MJ, De Jager PL, de Bakker PI, Gabriel SB, Mirel DB, Ivinson AJ, Pericak-Vance MA, Gregory SG, Rioux JD, McCauley JL, Haines JL, Barcellos LF, Cree B, Oksenberg JR, Hauser SL (2007): Risk alleles for multiple sclerosis identified by a genomewide study, N Engl J Med. $\underline{357(9): ~ 851-62 ~}$

27. Harauz G, Ladizhansky V, Boggs JM (2009): Structural polymorphism and multifunctionality of myelin basic protein, Biochemistry 48(34):8094-104

28. Hein T, Hopfenmüller W (2000): Projection of the number of multiple sclerosis patients in germany, Nervenarzt $\underline{71}(4): 288-94$

29. Hoe E, McKay F, Schibeci S, Heard R, Stewart G, Booth D (2010): Interleukin 7 receptor alpha chain haplotypes vary in their influence on multiple sclerosis susceptibility and response to interferon beta, J Interferon Cytokine Res. 30(5):291-8

30. Jacobs LD, Beck RW, Simon JH, Kinkel RP, Brownscheidle CM, Murray TJ, Simonian NA, Slasor PJ, Sandrock AW (2000): Intramuscular interferon beta-1a therapy initiated during a first demyelinating event in multiple sclerosis, N Engl J Med. 343(13):898-904

31. Kaplan MR, Meyer-Franke A, Lambert S, Bennett V, Duncan ID, Levinson SR, Barres BA (1997): Induction of sodium channel clustering by oligodendrocytes, Nature 386(6626):724-8.

32. Kappos L, Polman CH, Freedman MS, Edan G, Hartung HP, Miller DH, Montalban X, Barkhof F, Bauer L, Jakobs P, Pohl C, Sandbrink R (2006): Treatment with interferon beta- $1 \mathrm{~b}$ delays conversion to clinically definite and McDonald MS in patients with clinically isolated syndromes, Neurology $\underline{67(7): 1242-9}$

33. Kappos L, Freedman MS, Polman CH, Edan G, Hartung HP, Miller DH, Montalbán X, Barkhof F, Radü EW, Bauer L, Dahms S, Lanius V, Pohl C, Sandbrink R; BENEFIT Study Group (2007): Effect of early versus delayed interferone beta-1b treatment on disability after a first clinical event suggestive of multiple sclerosis: a 3-year follow up analysis of the BENEFIT study, Lancet 370(9585):389-97 
34. Keegan M, König F, McClelland R, Brück W, Morales Y, Bitsch A, Panitch H, Lassmann H, Weinshenker B, Rodriguez M, Parisi J, Lucchinetti CF (2005): Relation between humoral pathological changes in multiple sclerosis and response to therapeutic plasma exchange, Lancet $\underline{366}(9485): 579-82$

35. Khalil M, Reindl M, Lutterotti A, Kuenz B, Ehling R, Gneiss C, Lackner P, Deisenhammer F, Berger T (2006): Epitope specificity of serum antibodies directed against the extracellular domain of myelin oligodendrocyte glycoprotein: Influence of relapses and immunomodulatory treatments, J Neuroimmunol. 174(1-2):147-56

36. Kinkel RP, Dontchev M, Kollman C, Skaramagas TT, O'Connor PW, Simon JH; Controlled High-Risk Avonex Multiple Sclerosis Prevention Study in Ongoing Neurological Surveillance Investigators (2012): Association between immediate initiation of intramuscular interferon beta-1a at the time of a clinically isolated syndrome and long-term outcomes: a 10-year follow-up of the Controlled High-Risk Avonex Multiple Sclerosis Prevention Study in Ongoing Neurological Surveillance, Arch Neurol. 69(2):183-90

37. Kitley J, Woodhall M, Waters P, Leite MI, Devenney E, Craig J, Palace J, Vincent A (2012): Myelin-oligodendrocyte glycoprotein antibodies in adults with a neuromyelitis optica phenotype, Neurology Sep 18;고(12):1273-7. doi: 10.1212/WNL.0b013e31826aac4e

38. Klawiter EC, Piccio L, Lyons JA, Mikesell R, O'Connor KC, Cross AH (2010): Elevated intrathecal myelin oligodendrocyte glycoprotein antibodies in multiple sclerosis, Arch Neurol. 67(9):1102-8. doi: 10.1001/archneurol.2010.197.

39. Kohriyama T (2011): Clinically isolated syndrome: prognostic markers for conversion to multiple sclerosis and initiation of disease-modifying therapy, Rinsho Shinkeigaku. $\underline{51}(3): 179-87$

40. Kuhle J, Pohl C, Mehling M, Edan G, Freedman MS, Hartung HP, Polman CH, Miller DH, Montalban X, Barkhof F, Bauer L, Dahms S, Lindberg R, Kappos L, Sandbrink R (2007): Lack of association between antimyelin antibodies and progression to multiple sclerosis, $\mathrm{N}$ Engl J Med. $\underline{356}(4): 371-8$

41. Kursula P (2008): Structural properties of proteins specific to the myelin sheath, Amino Acids. 34(2):175-85.

42. Kurtzke JF (1983): Rating neurologic impairment in multiple sclerosis: an expanded disability status scale (EDSS), Neurology Nov; $\underline{33}(11): 1444-52$

43. Kurtzke JF (2000 a): Epidemiology of multiple sclerosis. Does this really point toward an etiology? Lectio Doctoralis, Neurol Sci. 21(6): 383-403

44. Kurtzke JF (2000 b): Multiple sclerosis in time and space--geographic clues to cause, J 
45. Lalive PH, Menge T, Delarasse C, Della Gaspera B, Pham-Dinh D, Villoslada P, von Büdingen HC, Genain CP (2006): Antibodies to native myelin oligodendrocyte glycoprotein serologic markers of early inflammation in multiple sclerosis, Proc Natl Acad Sci U S A. 103(7):2280-5

46. Lampasona V, Franciotta D, Furlan R, Zanaboni S, Fazio R, Bonifacio E, Comi G, Martino G (2004): Similar low frequency of anti-MOG IgG and IgM in MS patients and healthy subjects, Neurology 62(11):2092-4

47. Lassmann H, Brück W, Lucchinetti C (2001): Heterogeneity of multiple sclerosis pathogenesis: implications for diagnosis and therapy, Trends Mol Med. $\underline{7}(3): 115-21$

48. Lebrun C, Bensa C, Debouverie M, Wiertlevski S, Brassat D, de Seze J, Rumbach L, Pelletier J, Labauge P, Brochet B, Tourbah A, Clavelou P; Club Francophone de la Sclérose en Plaques (2009): Association between clinical conversion to multiple sclerosis in radiologically isolated syndrome and magnetic resonance imaging, cerebrospinal fluid, and visual evoked potential: follow-up of 70 patients, Arch Neurol. $\underline{66}(7): 841-6$

49. Lim ET, Berger T, Reindl M, Dalton CM, Fernando K, Keir G, Thompson EJ, Miller DH, Giovannoni G (2005): Anti-myelin antibodies do not allow earlier diagnosis of multiple sclerosis, Mult Scler. 11(4):492-4

50. Linington C, Bradl M, Lassmann H, Brunner C, Vass K (1988): Augmentation of demyelination in rat acute allergic encephalomyelitis by circulating mouse monoclonal antibodies directed against a myelin/oligodendrocyte glycoprotein, Am J Pathol. 130(3):443- 54

51. Linker RA, Chan A, Sommer M, Koziolek M, Müller GA, Paulus W, Gold R (2007): Plasma exchange therapy for steroid-refractory superimposed relapses in secondary progressive multiple sclerosis, J Neurol. 254(9):1288-9

52. Lucchinetti C, Brück W, Parisi J, Scheithauer B, Rodriguez M, Lassmann H (2000): Heterogeneity of multiple sclerosis lesions: implications for the pathogenesis of demyelination, Ann Neurol. 47(6):707-17

53. Lucchinetti CF, Mandler RN, McGavern D, Bruck W, Gleich G, Ransohoff RM, Trebst C, Weinshenker B, Wingerchuk D, Parisi JE, Lassmann H (2002): A role for humoral mechanisms in the pathogenesis of Devic's neuromyelitis optica, Brain 125(Pt 7):1450-61

54. Lyons JA, Ramsbottom MJ, Cross AH (2002): Critical role of antigen-specific antibody in 
experimental autoimmune encephalomyelitis induced by recombinant myelin oligodendrocyte glycoprotein, Eur J Immunol. 32(7):1905-13

55. Mader S, Gredler V, Schanda K, Rostasy K, Dujmovic I, Pfaller K, Lutterotti A, Jarius S, Di Pauli F, Kuenz B (2011): Complement activating antibodies to myelin oligodendrocyte glycoprotein in neuromyelitis optica and related disorders, J Neuroinflammation $\underline{8}: 184$

56. Maghzi A, Ghazavi H, Ahsan M, Etemadifar M, Mousavi S, Khorvash F, Minagar A (2010): Increasing female preponderance of multiple sclerosis in Isphahan, Iran: a population based study, Mult Scler. 16(3): 359-61

57. Marcus, J, Waubant, E (2013): Updates on Clinically Isolated Syndrome and Diagnostic Criteria for Multiple Sclerosis, Neurohospitalist; $\underline{3}(2)$ : 65-80

58. Marta C, Oliver A, Sweet R, Pfeiffer S, Ruddle N (2005): Pathogenic myelin oligodendrocyte glycoprotein antibodies recognize glycosylated epitopes and perturb oligodendrocyte physiology, Proc Natl Acad Sci U S A. 102(39): 13992-13997

59. McLaughlin K, Chitnis T, Newcombe J, Franz B, Kennedy J, McArdel S, Kuhle J, Kappos L, Rostasy K, Pohl D (2009): Age-dependent B cell Autoimmunity to a Myelin Surface Antigen in Pediatric Multiple Sclerosis, J Immunol. 183(6): 4067-4076

60. Menge T, Lalive PH, von Büdingen HC, Genain CP (2011): "Conformational epitopes of myelin oligodendrocyte glycoproteine are targets of potentially pathologic antibody responses in multiple sclerosis", J Neuroinflammation. 17(8): 161

61. Menge T, Lalive PH, von Büdingen HC, Cree B, Hauser SL, Genain CP (2005): Antibody responses against galactocerebroside are potential stage-specific biomarkers in multiple sclerosis, J Allergy Clin Immunol. 116(2): 453-9

62. Newman S, Kitamura K, Campagnoni AT (1987): Identification of a cDNA coding for a fifth form of myelin basic protein in mouse, Proc Natl Acad Sci U S A. $\underline{84}$ (3):886-90

63. Nischwitz S, Cepok S, Kroner A, Wolf C, Knop M, Müller-Sarnowski F, Pfister H, Roeske D, Rieckmann P, Hemmer B, Ising M, Uhr M, Bettecken T, Holsboer F, MüllerMyhsok B, Weber F (2010): Evidence for VAV2 and ZNF433 as susceptibility genes for multiple sclerosis, J Neuroimmunol. 227(1-2):162-6

64. O'Connor KC, Appel H, Bregoli L, Call ME, Catz I, Chan JA, Moore NH, Warren KG, Wong SJ, Hafler DA, Wucherpfennig KW (2005): Antibodies from inflamed central nervous system tissue recognize myelin oligodendrocyte glycoprotein, J Immunol. 175(3):1974-82

65. Okuda DT, Mowry EM, Beheshtian A, Waubant E, Baranzini SE, Goodin DS, Hauser SL, Pelletier D (2009): Incidental MRI anomalies suggestive of multiple sclerosis: the radiologically isolated syndrome, Neurology. $\underline{72}(9): 800-5$

66. Omlin FX, Webster HD, Palkovits CG, Cohen SR (1982): Immunocytochemical localization 
of basic protein in major dense line regions of central and peripheral myelin, $\mathrm{J}$ Cell Biol. 95(1):242-8.

67. Orton SM, Ramagopalan SV, Brocklebank D, Herrera BM, Dyment DA, Yee IM, Sadovnick AD, Ebers GC (2010): Effect of immigration on multiple sclerosis sex ratio in Canada: the Canadian Collaborative Study, J Neurol Neurosurg Psychiatry. $\underline{\text { 81(1):31-6 }}$

68. Prokopenko I, Montomoli C, Ferrai R, Musu L, Piras ML, Ticca A, Murgia BS, Bernardinelli L (2003): Risk for relatives of patients with multiple sclerosis in central Sardinia, Italy, Neuroepidemiology. 22(5): 290-6.

69. Raine CS, Cannella B, Hauser SL, Genain CP (1999): Demyelination in primate autoimmune encephalomyelitis and acute multiple sclerosis lesions: a case for antigenspecific antibody mediation, Ann Neurol. $\underline{46}(2): 144-60$

70. Rauer S, Euler B, Reindl M, Berger T (2006): Antimyelin antibodies and the risk of relapse in patients with a primary demyelinating event, J Neurol Neurosurg Psychiatry. 77(6): 739742

71. Rieckmann P (2005): Neurodegeneration and clinical relevance for early treatment in multiple sclerosis, Int MS J. 12(2):42-51

72. Sadovnick AD, Risch NJ, Ebers GC (1998): Canadian collaborative project on genetic susceptibility to MS, phase 2: rationale and method. Canadian Collaborative Study Group, Can J Neurol Sci. 25(3): 216-21.

73. Sadovnick AD, Diercks A, Ebers GC (1999): Genetic counselling in multiple sclerosis: risks to sibs and children of affected individuals, Clin Genet. $\underline{56}(2): 118-22$

74. Sawcer S, Hellenthal G, Pirinen M, Spencer CC, Patsopoulos NA, Moutsianas L, Dilthey A, Su Z, Freeman C, Hunt SE, Edkins S (2011): Genetic risk and a primary role for cellmediated immune mechanisms in multiple sclerosis, Nature. 476(7359):214-9

75. Schilling S, Linker RA, König FB, Koziolek M, Bähr M, Müller GA, Paulus W, Gärtner J, Brück W, Chan A, Gold R (2006): Plasma exchange therapy for steroid-unresponsive multiple sclerosis relapses: clinical experience with 16 patients, Nervenarzt 77(4):430-8

76. Schmidt R, Hoffmann F (2006): Multiple Sklerose, Urban und Fischer, München, 4 . Auflage

77. Schulz M, Dotzlaw H, Mikkat S, Eggert M, Neck G (2007): Proteomic Analysis of Peripheral Blood Mononuclear Cells: Selective Protein Processing Observed in Patients with Rheumatoid Arthiritis, J Proteome Res. $\underline{6}(9): 3752-9$

78. Sellner J, Schirmer L, Hemmer B, Mühlau M (2010): The radiologically isolated 
syndrome: take action when the unexpected is uncovered?, J Neurol. 257(10):1602-11

79. Siva A, Saip S, Altintas A, Jacob A, Keegan BM, Kantarci OH (2009): Multiple sclerosis risk in radiologically uncovered asymptomatic possible inflammatory-demyelinating disease, Mult Scler. 15(8):918-27

80. Srivastava R, Aslam M, Kalluri SR, Schirmer L, Buck D, Tackenberg B, Rothhammer V, Chan A, Gold R, Berthele A, Bennett JL, Korn T, Hemmer B (2012): Potassium channel KIR4.1 as an immune target in multiple sclerosis, N Eng1 J Med. 367(2):115-23

81. Takahashi N, Roach A, Teplow DB, Prusiner SB, Hood L (1985): Cloning and characterization of the myelin basic protein gene from mouse: one gene can encode both 14 $\mathrm{kd}$ and $18.5 \mathrm{kd}$ MBPs by alternate use of exons, Cell $\underline{42}(1): 139-48$

82. Tintoré M (2008): Rationale for early intervention with immunomodulatory treatments, $\mathrm{J}$ Neurol. 255 Suppl 1:37-43

83. Tomassini V, De Giglio L, Reindl M, Russo P, Pestalozza I, Pantano P, Berger T, Pozzilli C (2007): Anti-myelin antibodies predict the clinical outcome after a first episode suggestive of MS, Mult Scler. 13(9):1086-94

84. von Büdingen HC, Hauser S, Fuhrmann A, Nabavi C, Lee J, Genain C (2002): Molecular characterization of antibody specificities against myelin/oligodendrocyte glycoprotein in autoimmune demyelination, Proc Natl Acad Sci U S A. 99(12): 8207-8212

85. Wallin MT, Page WF, Kurtzke JF (2004): Multiple sclerosis in US veterans of the Vietnam era and later military service: race, sex, and geography, Ann Neurol. 55(1):65-71

86. Wang H, Munger KL, Reindl M, O’Reilly EJ, Levin LI, Berger T, Ascherio A (2008): Myelin oligodendrocyte glycoprotein antibodies and multiple sclerosis in healthy young adults, Neurology 7;71(15):1142-6

87. Weber F, Fontaine B, Cournu-Rebeix I, Kroner A, Knop M, Lutz S, Müller-Sarnowski F, Uhr M, Bettecken T, Kohli M, Ripke S, Ising M, Rieckmann P, Brassat D, Semana G, Babron MC, Mrejen S, Gout C, Lyon-Caen O, Yaouanq J, Edan G, Clanet M, Holsboer F, Clerget-Darpoux F, Müller-Myhsok B (2008): IL2RA and IL7RA genes confer susceptibility for multiple sclerosis in two independent European populations, Genes Immun. $\underline{9}(3): 259-63$

88. Webster Hd, Aström KE (2009): Gliogenesis: historical perspectives, 1839-1985, Adv Anat Embryol Cell Biol. 202:1-109

89. Wingerchuk D, Weinshenker B (2000): Multiple sclerosis: epidemiology, genetics, classification, natural history and clinical outcome measures, Neuroimaging Clin N Am. 
10(4): $611-24$

90. Xu Y, Zhang Y, Liu CY, Peng B, Wang JM, Zhang XJ, Li HF, Cui LY (2012): Serum antibodies to 25 myelin oligodendrocyte glycoprotein epitopes in multiple sclerosis and neuromyelitis optica: clinical value for diagnosis and disease activity, Chin Med J (Engl). $\underline{125}(18): 3207-10$

91. Zhou D, Srivastava R, Nessler S, Grummel V, Sommer N, Brück W, Hartung HP, Stadelmann C, Hemmer B (2006): Identification of a pathogenic antibody response to native myelin oligodendrocyte glycoprotein in multiple sclerosis, Proc Natl Acad Sci U S A. 103(50): 19057-19062

92. Zivadinov R, Havrdová E, Bergsland N, Tyblova M, Hagemeier J, Seidl Z, Dwyer MG, Vaneckova M, Krasensky J, Carl E, Kalincik T, Horáková D (2013): Thalamic Atrophy is Associated with Development of Clinically Definite Multiple Sclerosis, Radiology 268(3):831-41 


\section{Lebenslauf}

Ich wurde in Rosenheim am 25.05.1981 als dritte Tochter von Frau Dr. Irene Franke und Herrn Dr. Walter Franke geboren. Meine schulische Ausbildung mit Grundschule und Besuch des Gymnasiums absolvierte ich in den städtischen Schulen Bad Aiblings in den Jahren 1987 - 2000. An Fremdsprachen lernte ich ab der 5. Klasse Englisch, ab der 7. Klasse Latein sowie ab der 9. Klasse Italienisch, wobei ich im Jahr 1997 an einem Austauschprogramm mit der Stadt La Spezia teilnahm. In der 11. Klasse wurde ich im Fach Geschichte auf Italienisch unterrichtet. Im selben Zeitraum belegte ich einen Wahlkurs Französisch. Während der Sommerferien '99 absolvierte ich ein Praktikum als Krankenpflegehelferin in der psychiatrischen Abteilung des Bezirkskrankenhauses Gabersee, während auch der Entschluss zum Studium der Humanmedizin reifte.

Nach dem Abschluß des Abiturs mit der Note 2,1 arbeitete ich innerhalb eines freiwilligen sozialen Jahres von 09/00 bis 03/01 in der onkologischen Fachklinik Bad Trissl als Krankenpflegehelferin. (Nach Erhalt des Studienplatzes in meiner Wunschstadt Göttingen durfte ich dieses schon nach einem halben Jahr abschliessen.)

Im SS01 begann mein Medizinstudium an der Georg-August-Universtät in Göttingen. Den Ersten Abschnitt der Ärztlichen Prüfung (Physikum) legte ich im September '04 ab. Vom Mai '05 bis zum Juni '07 arbeitete ich als Krankenpflegehelferin in der anästhesiologischen Abteilung des Krankenhauses Neu-Bethlehem in Göttingen. Von Januar '05 bis zum Januar '07 war ich Mitglied der Truppe freiwilliger Helfer im DRK Göttingen. Im Mai '05 begann ich mit der Forschungsreihe für die Dissertation am Institut für MS-Forschung in Göttingen. Während meines Praktischen Jahres, welches ich im Diakoniekrankenhaus Rotenburg/ Wümme von $08 / 07$ bis $11 / 08$ mit dem Wahlfach Neurochirurgie absolvierte, wurde am 12.01.08 mein Sohn Vincent Konstantin Humboldt geboren. Den Zweiten Abschnitt der Ärztlichen Prüfung schloss ich mit dem mündlichen Examen im Juni '09 mit der Gesamtnote 2,5 ab.

Von 15.07.09 bis zum 31.03.12 arbeitete ich als Assistenzärtin für Neurochirurgie im 
Diakoniekrankenhaus Rotenburg/Wümme. Es folgte der Umzug nach Murnau und die Arbeit am BG-Unfallkrankenhaus Murnau ab dem 01.04.12. Aus persönlichen und familiären Gründen kündigte ich diese Arbeit zum 01.07.13 und bin seitdem Hausfrau und Mutter. Die Geburt meines zweiten Kindes erwarte ich um den 15.02.14.

\section{Danksagung}

Mein größter Dank gilt natürlich Herrn Prof. Gold und meinem Doktorvater PD Dr. Andrew Chan. Beginnend mit der Überlassung des Themas und dem Vertrauen, welches er mir damit geschenkt hat, stand er mir während der gesamten Versuchsphase jederzeit mit Rat und Tat zur Seite. Nicht zuletzt möchte ich mich bei ihm für die endlose Geduld und die konstruktive Kritik bei der schriftlichen Erstellung dieser Arbeit bedanken.

Für die Einarbeitung in die allgemeine und spezielle Laborarbeit möchte ich mich bei allen Mitarbeitern (oder mittlerweile ehemaligen Mitarbeitern) des Institutes für MS-Forschung in Göttingen bedanken. Besonders hervorheben möchte ich hier Frau Christiane Westermann, ohne die ich die Massen an Unterlagen vermutlich niemals bewältigt hätte. Außerdem Frau Annette Horn, die mir geduldig die Geräte und Apperaturen nahegebracht hat sowie bei zeitlichen oder persönlichen Problemen immer zur Seite stand. Auch die zu dieser Zeit dort tätigen Doktoren und zukünftigen Doktoren möchte ich nicht vergessen, namentlich vor allem Frau Dr. Simone Wüst, Frau Dr. Ines Siglienti, Frau Dr. Sabine Schilling, Herr Dr. Ralf Linker, Frau Dr. Steffi Cotte, Herr Dr. Fred Lühder, die bei technischen oder theoretischen Fragen jederzeit ein offenes Ohr boten.

Vielen Dank Euch allen! 